\title{
Formation of linear planform chimneys controlled by preferential hydrocarbon leakage and anisotropic stresses in faulted fine-grained sediments, offshore Angola
}

\author{
Sutieng Ho ${ }^{1,5,6}$, Martin Hovland ${ }^{2,6}$, Jean-Philippe Blouet ${ }^{3,6,7}$, Andreas Wetzel ${ }^{4,6}$, Patrice Imbert ${ }^{5,6}$, and \\ Daniel Carruthers ${ }^{8}$ \\ ${ }^{1}$ Department of Geosciences, National Taiwan University, P.O. Box 13-318, 106 Taipei, Taiwan \\ ${ }^{2}$ Center for Geobiology, University of Bergen, Postboks 7803, 5020 Bergen, Norway \\ ${ }^{3}$ Unit of Earth Sciences, Fribourg University, Chemin du Musée 6, 1700 Fribourg, Switzerland \\ ${ }^{4}$ Geological Institute, University of Basel, Bernoullistrassse 32, 4056 Basel, Switzerland \\ ${ }^{5}$ Total-CSTJF, Avenue Larribau, Pau 64000, France \\ ${ }^{6}$ Fluid Venting System Research Group, Nancy 54000, France \\ ${ }^{7}$ Department of Geosciences, Université Libre de Bruxelles, Avenue Franklin Roosevelt 50, 1050 Brussels, Belgium \\ ${ }^{8}$ CGG MCNV, GeoSolutions, Llandudno, North Wales, LL30 1SA, UK
}

Correspondence: Sutieng Ho (sutiengho@gmail.com, sutieng.ho@ fluid-venting-system.org) and Jean-Philippe Blouet (jeanphilippe.blouet@gmail.com, jean-philippe.blouet@fluid-venting-system.org)

Received: 24 April 2018 - Discussion started: 17 May 2018

Revised: 18 November 2018 - Accepted: 23 November 2018 - Published: 12 December 2018

\begin{abstract}
A new type of gas chimney exhibiting an unconventional linear planform is found. These chimneys are termed "Linear Chimneys", which have been observed in 3D seismic data offshore of Angola. Linear Chimneys occur parallel to adjacent faults, often within preferentially oriented tier-bound fault networks of diagenetic origin (also known as anisotropic polygonal faults, $\mathrm{PFs}$ ), in salt-deformational domains. These anisotropic PFs are parallel to salt-tectonicrelated structures, indicating their submission to horizontal stress perturbations generated by the latter. Only in areas with these anisotropic PF arrangements do chimneys and their associated gas-related structures, such as methane-derived authigenic carbonates and pockmarks, have linear planforms. In areas with the classic "isotropic" polygonal fault arrangements, the stress state is isotropic, and gas expulsion structures of the same range of sizes exhibit circular geometry. These events indicate that chimney's linear planform is heavily influenced by stress anisotropy around faults. The initiation of polygonal faulting occurred 40 to $80 \mathrm{~m}$ below the present day seafloor and predates Linear Chimney formation. The majority of Linear Chimneys nucleated in the lower part of the PF tier below the impermeable portion of fault planes and a regional impermeable barrier within the PF tier. The
\end{abstract}

existence of polygonal fault-bound traps in the lower part of the PF tier is evidenced by PF cells filled with gas. These $\mathrm{PF}$ gas traps restricted the leakage points of overpressured gas-charged fluids along the lower portion of PFs, hence controlling the nucleation sites of chimneys. Gas expulsion along the lower portion of PFs preconfigured the spatial organisation of chimneys. Anisotropic stress conditions surrounding tectonic and anisotropic polygonal faults coupled with the impermeability of PFs determined the directions of long-term gas migration and linear geometries of chimneys. Methane-related carbonates that precipitated above Linear Chimneys inherited the same linear planform geometry, and both structures record the timing of gas leakage and palaeostress state; thus, they can be used as a tool to reconstruct orientations of stress in sedimentary successions. This study demonstrates that overpressure hydrocarbon migration via hydrofracturing may be energetically more favourable than migration along pre-existing faults. 


\section{Introduction}

Hydrocarbon migration is directly impacted by structures such as faults and salt diapirs (Roberts and Carney, 1997; Talukder, 2012; Plaza-Faverola et al., 2012, 2015). Flow directions in the subsurface and the distribution of hydrocarbon leakage sites at the seafloor are preconfigured by such preexisting structures (Thrasher et al., 1996; Moore et al., 1990). The morphology of structures formed during fluid leakage records the style and intensity of fluid expulsion and is thus useful for deciphering the fluid migration history (Roberts et al., 2006; Blouet et al., 2017; Imbert et al., 2017; Imbert and Ho, 2012; Ho et al., 2012b, 2018). As 3-D seismic reflection data have played an increasingly important role in visualisation and identification of fluid flow features (Heggland, 1997), by conducting seismic analyses for vertical successions of fluid leakage expressions around faults, such as gas chimneys feeding pockmarks and seep carbonates, it is possible to unravel the timing and pathways of migrating fluids and the sealing efficiency of faults (Ligtenberg, 2005; PlazaFaverola et al., 2012; Ho et al., 2016).

Recent studies from the upper slope of the Lower Congo Basin have revealed the existence of a new type of chimney (Ho et al., 2016; Ho, 2013). Chimneys are usually circular in planform. The chimneys described in this study, however, are distinctly linear, display an extraordinary parallelism with adjacent faults in map view, and have been termed previously "Linear Chimneys" (sensu Ho et al., 2013, 2016). Chimneys with non-circular planforms were first observed in the 1980s. Hovland (1983) documented chimneys in high-resolution 2D seismic data from the North Sea exhibiting irregular and elongate planform geometries with rounded summits and variable widths and lengths ranging from several hundred metres to more than $1 \mathrm{~km}$. They were interpreted as a result of gas escaping along fractures and/or faults from the apices of underlying sedimentary folds (Hovland, 1983, 1984). In modern 3-D seismic data, Hustoft et al. (2010) documented chimneys having elliptical cross sections and were the first to analyse the planform ratio of chimneys. Hustoft et al. (2010) suggested that the preferred orientation of the long axis of the elliptical planforms of chimneys was caused by local stress perturbations associated with adjacent tectonic structures. In contrast to the chimneys described by Hovland (1983), the Linear Chimneys occurring in the Lower Congo Basin are string-like in plan view, vary little in width, and have blunt terminations often with sharp tips as well as being rooted along and parallel to fault planes. This geometrical arrangement suggests that the near-fault stress field affected the formation of the Linear Chimneys (Ho et al., 2012a). Previously, Ho (2013) and Ho et al. (2016) used intersecting positions of Linear Chimneys and faults to determine the fault's permeability, and they suggested that overpressured gas-charged fluids cannot migrate further upwards of the fault plane and therefore escape upwards forming vertical chimneys. However, the factors that determine the linear planform of these chimneys and their collective orientation have not yet been investigated.

The role of stresses in controlling the orientations of venting structures, hydraulic fractures, and redirecting fluid flow has been well documented (see Nakamura, 1977; PlazaFaverola et al., 2015). Detailed studies of the relationship between stress state, fault orientation, tectonic structures, and injectites have been carried out by Bureau (2014), who demonstrated that sand injectites preferentially intrude preexisting polygonal faults along the extensional direction of adjacent tectonic structures. Nakamura (1977) studied interactions between the orientation of magmatic fluid conduits and tectonic stresses. Nakamura established a conceptual framework relating the orientation of magmatic dykes to regional stress perturbations generated under different tectonic regimes; for instance, linear zones of eruptions occur parallel to fault lines under extensional tectonic regimes, while zones of eruptions form at high angles with faults in compressive tectonic areas (Nakamura, 1977). Consequently, faulting and near-fault stress state can play an important role in fluid migrations, hence the formation and geometric development of fluid flow structures.

In this case study, Linear Chimneys are associated with networks of tier-bound, small, densely spaced normal faults which have a polygonal organisation in map view. Polygonal networks of discontinuities affecting discrete intervals of fine-grained sediment have previously been linked to diagenetic processes by Berkson et al. (1973). They were first identified as tiered fault systems by Henriet et al. (1982, 1988, 1991) and investigated in detail by Verschuren (1992). They were later called polygonal fault (PF) systems by Cartwright (1994) (see Clausen et al., 1999; Goulty, 2008), although other observations show that these faults can host a whole range of different planform geometries, including concentric patterns (see Stewart, 2006; Chopra and Marfurt, 2007).

Generally, polygonal faults are considered non-tectonic fault systems arising due to compactional dewatering of very fine-grained sediments during the early stages of burial in passively subsiding sedimentary basins (Henriet et al., 1988). In the classic examples of these fault systems which show "polygonal" fault arrangements and also contribute to their nomenclature, they were characterised by very small differences between the horizontal principal stresses during their formation (Cartwright, 1994; Carruthers et al., 2013). The examples of polygonal faults in this case study show substantial departures from this classic polygonal fault pattern (so-called isotropic PFs) to very polarised fault arrangements (so-called anisotropic PFs) in which the tier is deformed by salt tectonic structures or offset by their associated fault systems (Fig. 1; Carruthers, 2012). These faults can display a variety of intricate patterns ranging from tight radial systems around salt diapirs to concentric systems within salt withdrawal basins and spiraling concentric patterns above buried pockmarks (Stewart, 2006; Ho et al., 2013). The preferen- 
tially aligned faults are many times longer than the regular fault segments with polygonal alignments but are often still confined to the same "tiers". The observations are consistent with a number of other reported examples of preferred fault alignments within networks of polygonal faults (Stewart, 2006; Ghalayini et al., 2016). The preferred fault alignments are indicative of horizontal stress anisotropy at the time of their formation (Carruthers et al., 2013).

Based on seismic observations, the objective of this study is to constrain the relative timing of fluid flow and polygonal faulting, thereby offering a fluid migration model for the affected interval. This model will be used as a platform to discuss the interactions between fluid flow, faults, and local stress states. Particularly, the following questions are addressed: (1) why are chimneys linear in planform and not circular or elliptical as observed elsewhere? (2) Why do they occur specifically along certain parts of PF planes?

\section{Data and methods}

The seismic data presented in this study extend across the outer shelf and upper slope of the Angolan continental margin (Lower Congo Basin) (Fig. 1). Two 3-D seismic surveys acquired in 2006 on behalf of Total S.A. have been used for principal investigation (Appendix Fig. A1). The larger of the two surveys covers an area of $1310 \mathrm{~km}^{2}$ at about $1000 \mathrm{~m}$ of water depth with a dominant frequency of $55-60 \mathrm{~Hz}$ and a vertical resolution of approximately $7 \mathrm{~m}$ down to about $1 \mathrm{~s}$ two-way travel time (TWT) below seafloor. The smaller survey within this area covers approximately $530 \mathrm{~km}^{2}$ with the dominant frequency being slightly higher $(70-80 \mathrm{~Hz})$, resulting in a higher vertical resolution of $5 \mathrm{~m}$. Both 3-D surveys have a bin size of $6.25 \times 6.25 \mathrm{~m}$ and a map resolution of $6.25 \mathrm{~m}$. They are multichannel, near-offset data that have been post-stacked, time-migrated, and zero-phased. The data are displayed in SEG normal polarity whereby a downward increase in acoustic impedance is represented by wavelets of positive amplitude, as shown in the figures in red. Here, the near-offset surveys are used for illustrations as they yield the highest vertical resolution and are optimal for mapping the details of small fluid venting structures. In addition, middleand far-offset volumes (representing the amplitude of the signal received at different angles of incidence) were all used for verifying the presence of studied features and to determine whether or not the studied features are seismic shadows of shallow anomalies. Local horizons intersected by fluid venting structures were analysed line by line and on arbitrary lines orthogonal to the structures to more accurately map out the linear fluid venting structures. Particularly, studied chimneys were screened for potential artefacts by combining cross section and map views, which are present on the near-, middle-, and far-offset volumes.

\section{Geological setting}

\subsection{Regional setting}

The Lower Congo Basin formed during the rifting and breakup of western Gondwana, followed by the opening of the central South Atlantic (Mascle and Phillips, 1972). Two main phases of sedimentation can be distinguished which broadly correspond to the rift and drift components of the basin's evolution. The rift sequence comprises extensional tilted fault blocks filled with Neocomian-Aptian siliciclastic sediments overlain by a succession of evaporites (Séranne and Anka, 2005). The drift sequence is composed of Albian carbonates and a Late Cretaceous-Cenozoic succession of siliciclastic sediments. Since the end of evaporite deposition the passive margin sequence has been gravitationally unstable, incrementally translating seaward on late Aptian evaporites (Duval et al., 1992). Translation was accommodated by upper slope extension and lower slope compression of the postsalt sediment cover (Séranne and Anka, 2005). The 3-D seismic survey is situated above the seaward end of this zone of extension comprising an assortment of minibasins and salt diapirs. This paper focuses on the relationship between fluid flow and geological structures in the Neogene-Quaternary upper drift sequence. The principal units are summarised in Fig. 2a.

\subsection{Structural setting of the study area}

\subsubsection{Salt-related structuration}

A large seaward-dipping listric growth fault rooted in the crest of a NW-SE-trending salt wall (dashed pink line on Fig. 1) divides the study area into a landward footwall domain and seaward hanging wall domain (Fig. 2a; Ho, 2013; Ho et al., 2018). On the seaward side of the fault, the Albian to early Cenozoic strata, capped by the purple horizon at 23.8 Ma, thickens into a turtle-back anticline (Fig. 2a). These thickness changes mark the first stages of salt-detached extension within the area.

Four, late Tertiary depocentres named Syncline-0, -1, -2, and -3 occur along the strike of the salt wall, situated in the hanging wall of the large listric growth fault (Figs. 1, 2a). These synclines developed during late-stage salt-detached extension in which the NW-SE-trending salt wall collapsed, forming the large listric growth fault which transects the survey. Syncline-0, -1 , and -2 are located adjacent to two salt diapirs (D1 and D2; Fig. 1), which are rooted in the salt wall at depth. Syncline-0 subsided from the Early Miocene (ca. 20 Ma) to Messinian (Ho, 2013). Syncline-1 and -2 subsided since approximately the early Middle Miocene (ca. 16.4 Ma) until the Miocene-Pliocene (Ho, 2013). Some extensional faults in the SW side of Syncline-2 next to chimney structures were still active during the Quaternary (see Fig. 6b in Ho et al., 2012a). The rollover Syncline-3 in the 


\subsection{Ma horizon dip map}

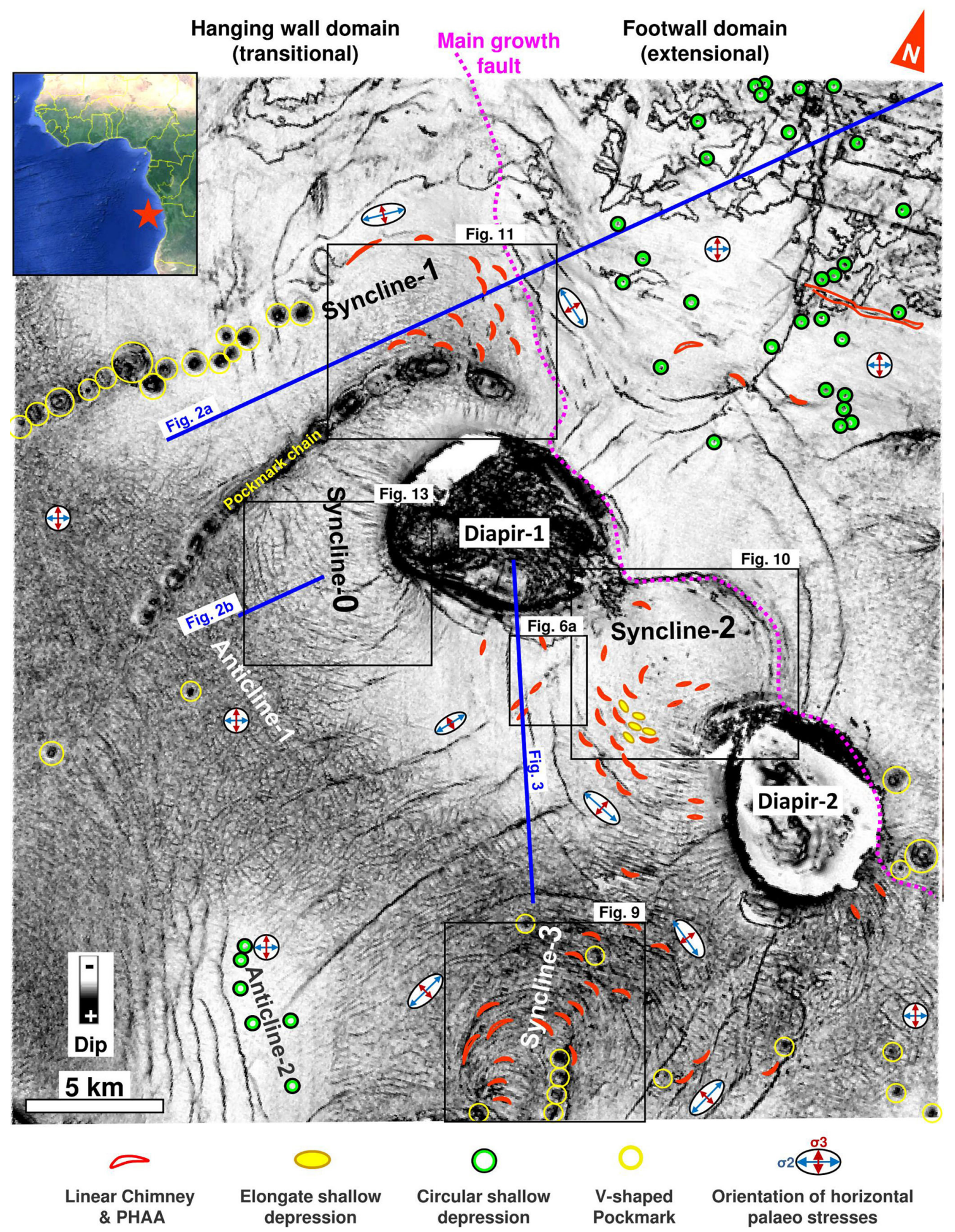

Figure 1. Dip map of referential horizon 5.3 Ma showing distributions of fluid expulsion structures across the study area. Subtypes of fluid expulsion features are shown diagrammatically (see legend below main figure). Palaeo-stress ellipses show relative directions and magnitudes of the horizontal principal stresses and are constructed from the planform geometry of the polygonal fault networks (see Sect. 3.2 .3 for more information). The blue axis and red axis on stress ellipses indicate the palaeo-orientation of the intermediate and minimum stresses, respectively. The location of the seismic survey is indicated by a red star on the insert map. 

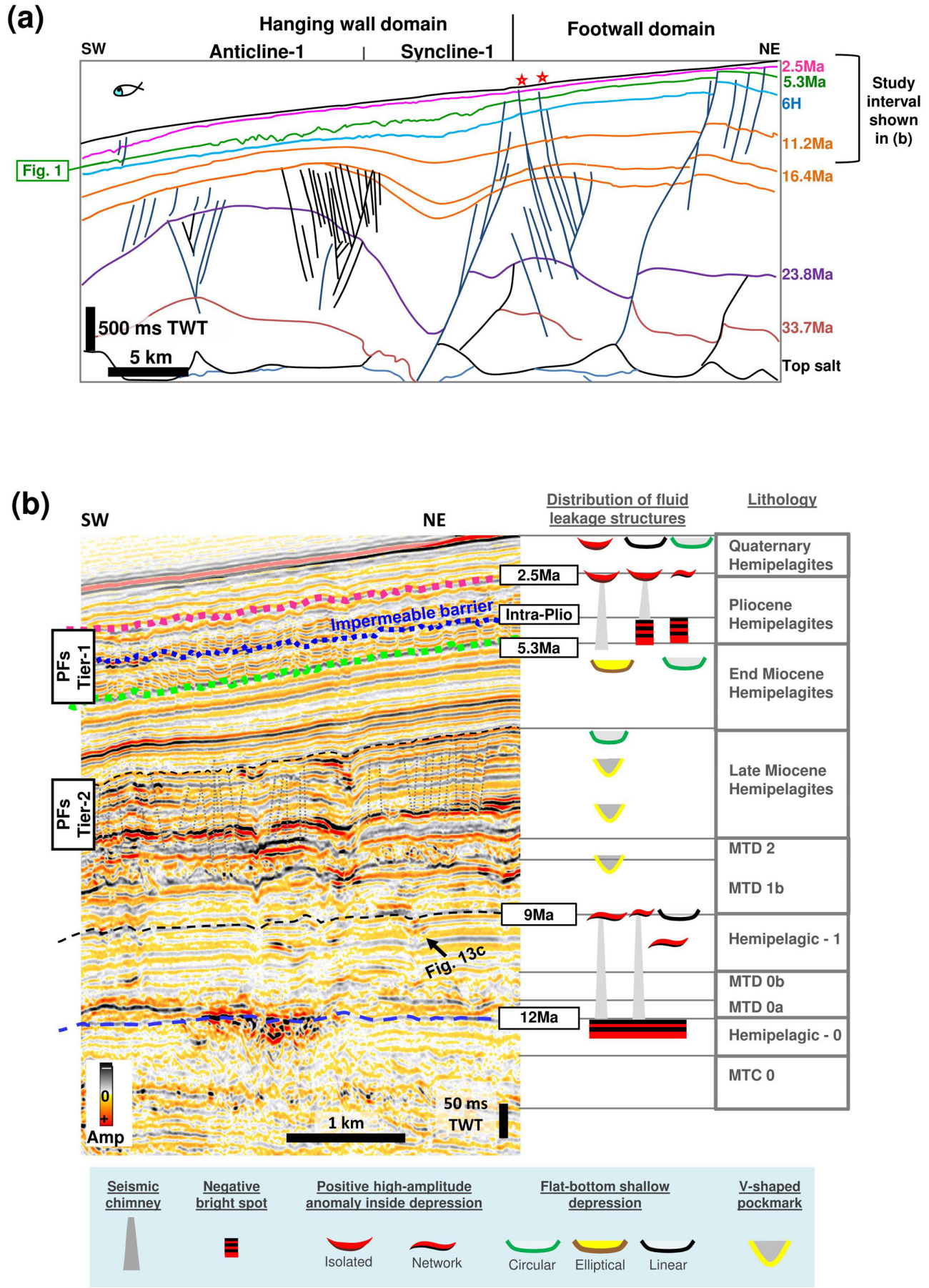

Figure 2. Geological setting. (a) Interpreted cross section through the study area. See Fig. 1 for location. Red stars indicate faults that were reactivated during the Quaternary. (b) Types of fluid expulsion structures and their distributions within the stratigraphic framework are shown to the right of seismic section. Horizons prefixed "H" and their approximate ages are shown. Figure adapted from Ho et al. (2012a) and Ho (2013).

south of the study area was induced by salt deflation during the early Pliocene and became inactive in the late Pliocene (Ho, 2013).

\subsubsection{Miocene to Quaternary stratigraphy and elements}

The fluid flow structures are located within the Middle Miocene to Quaternary strata, which are mainly composed of 
hemipelagites (Philippe, 2000) intercalated with mass transport complexes (Fig. 2b). In particular, the studied chimneys primarily occur within the Upper Miocene and Pliocene deposits within synclines (Fig. 2b). These intervals are deformed by polygonal faulting, which conforms to two distinct tiers, named here as Tier-1 and Tier-2 (Ho et al., 2012a, 2013, 2016, 2018; Ho, 2013).

The deepest Tier-1 ranges from $70-130 \mathrm{~m}$ thick and contains the Late Miocene units, whilst the shallower Tier-2 contains the Pliocene units and has a maximum thickness of ca. $250 \mathrm{~m}$. Tier-1 has a thicker pinch-out toward Diapir1 , while Tier- 2 shows a thinner pinch-out where polygonal faults become undetectable below $60 \mathrm{~ms}$ TWT (Fig. 3). These PFs often extend into strata above (e.g. interval A in Fig. 3a). The strata immediately overlying the PF intervals cover the relief of the horst and graben structures below and show constant thicknesses (e.g. interval B-C in Fig. 3a). Pockmarks associated with circular PF hosts can often be observed at the base of PF tiers (e.g. Fig. 3b-c; Carruthers, 2012; Ho et al., 2012a). In Tier-2, a regional impermeable barrier of the so-called "Intra-Pliocene" has been identified by its geophysical character and the vast presence of gas accumulations immediately below (Ho, 2013). The stratigraphic positions of venting structures are summarised in Fig. 2b.

\subsubsection{Organisation of PFs in the study area}

In this study area, PFs are organised into different patterns in map view, such as the isotropic polygonal fault pattern gradually reorganising to a system comprised of longer faults in a certain direction (i.e. referred to as anisotropic PFs), with shorter faults orthogonally intersecting them. The shorter faults are the same length as the standard polygonal fault segments, whilst the longer ones are up to 20 times longer (Carruthers, 2012). These long and short polygonal fault segments are referred to as first- and second-order PFs throughout this paper.

Preferred fault alignments or "anisotropic fault patterns" within polygonal fault networks have been observed in this study area. Concentric faults surround pockmarks (see Fig. 2a in Ho et al., 2013) and are parallel to extensional synclinal faults (Fig. A2b; see also red dotted lines on all maps of Syncline-3 hereafter). Radial faults occur around salt diapirs (Fig. A2c) (Carruthers, 2012), whilst ladder-like fault patterns occur in the centre of concentric fault patterns above Syncline-2 (Fig. A2d).

The orientations of the PFs around or above the aforementioned tectonic structures are not unusual as the fault patterns mantle the expected stress state of the structures (Carruthers, 2012; Carruthers et al., 2013). The direction of maximum horizontal stress around the tectonic structures is indicated by the first-order anisotropic PFs, while the horizontal minimum stress is indicated by the second-order anisotropic PFs (e.g. stress ellipses in Fig. 1), and hence different PF patterns are considered as indicators of the stress state in the host sediments (Carruthers, 2012; Carruthers et al., 2013).

Throughout this paper we will show that stress conditions and polygonal faulting in this area has had a profound impact on the subsequent phases of fluid flow by defining a number of interim traps. Consequently, it is important to outline the nomenclature used when referring to different scales of stresses and specific parts of the fault planes in this study.

- "Regional stress" refers to stress states in the subsurface driven by primary tectonic forces, which include gravity and the lateral extension and contraction occurring above the regional salt detachment.

- "Local stress" refers to stress state at the scale and within close proximity of individual tectonic structures where the regional stress field may be locally perturbed.

- "In situ stress" refers to stress conditions in place at the location of individual polygonal faults; this is particularly relevant when trying to understand the stress conditions at sites of incipient hydraulic fracture developments which lead to the formation of chimneys.

- "Lower footwall", when not specified, refers to the lower part of tilted PF blocks immediately adjacent to the fault, which moved upward, or referencing the lower part of horsts in this study area.

- "Lower hanging wall", when not specified, refers to the lower part of PF grabens.

\section{Observations}

Evidence for fluid flow around salt structures is provided by the occurrence of chimneys, pockmarks/depressions, positive high-amplitude anomalies (PHAAs), which are acoustically hard (increase in acoustic impedance) and interpreted as methane-derived authigenic carbonates, and negative highamplitude anomalies (NHAAs), which are acoustically soft (decrease in acoustic impedance) and interpreted as free gas (Coffeen, 1978; Petersen, 2010; Plaza-Faverola et al., 2011; Ho et al., 2012a). These structures are characterised by a linear-to-circular geometry in plan view (Fig. 2b).

\subsection{Linear chimneys}

\subsubsection{Acoustic properties of Linear Chimneys and terminations}

Chimneys have been observed worldwide in seismic data (see Løseth et al., 2011; Berndt et al., 2003; Hustoft et al., 2010; Plaza-Faverola et al., 2010; Ho et al., 2016). Seismic chimneys are represented by narrow vertical zones characterised by either stacked amplitude anomalies, pull-up, pushdown, or distorted reflections (Heggland, 2005; Hustoft et al., 2007, 2010; Petersen, 2010; Løseth et al., 2001, 2011). 


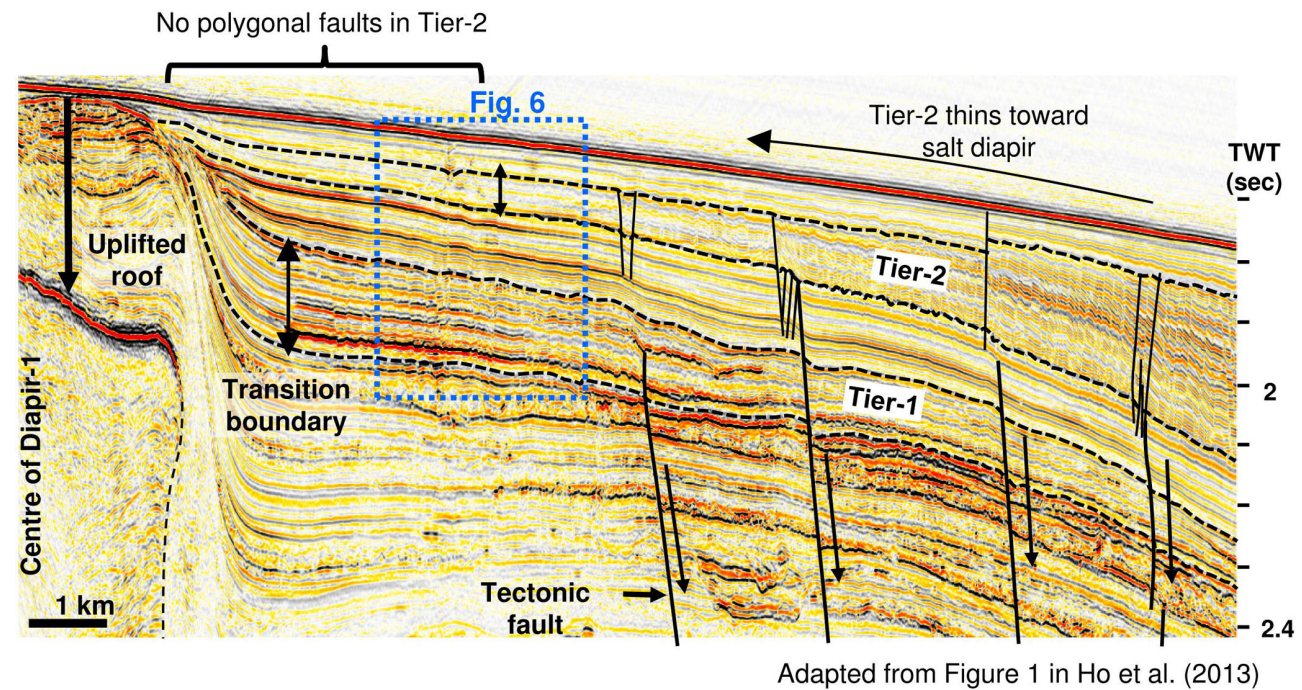

Figure 3. Arbitrary seismic line showing the pinch-out of polygonal fault tiers (defined by black dotted lines) against the SE flank of Diapir-1. Line location is shown in Fig. 1. The polygonal faults disappear beyond the black vertical arrows, progressively towards the pinch-out of the tier at the transitional boundary where the wedge thickness starts to be less than $60 \mathrm{~ms}$ TWT. Note that PFs are absent toward the pinch-out of Tier-2, but are present at the same location in Tier-1 below where this tier reaches its maximum thickness (Ho et al., 2013). This may provide additional support for the theory of minimum thickness determining PF growth (Carruthers, 2012). This observation can serve as a reference example for PF growth. Image adapted from Ho et al. (2013).

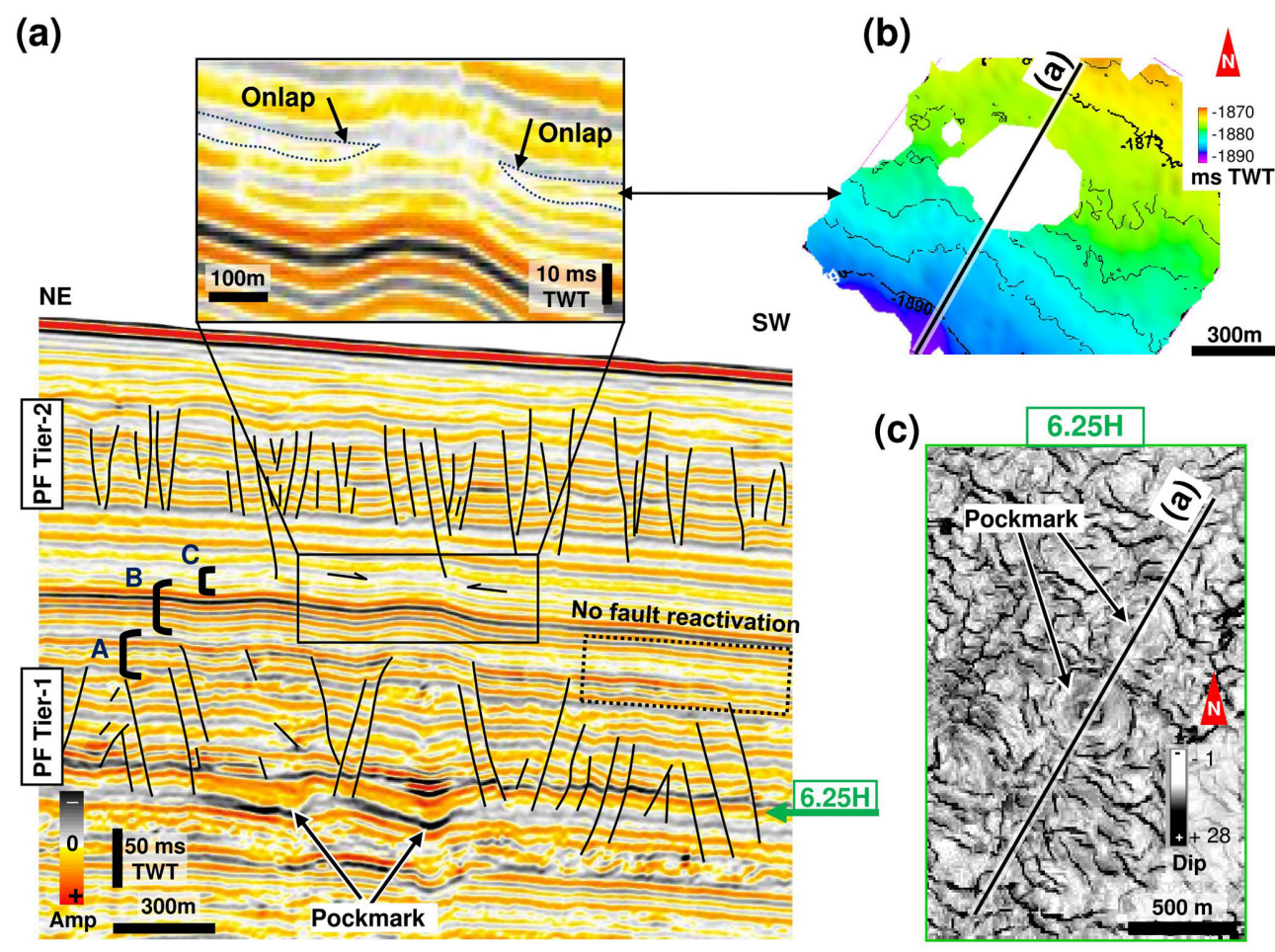

Figure 4. Direct evidence for the time when PF activity ceased. (a) Profile transecting outward-facing concentric faults (defining a horst block) above a buried pockmark (annotated) in PF Tier-1. A minority of fault upper tips exist in interval A above Tier-1 (interval A); the first non-faulted stratum (interval B) is folded above the horst with an isopachous thickness; the topmost reflection (in interval C) pinches out on the positive relief above the horst as indicated by black arrows. (b) Two-way time map of the onlap termination of the horizon (in interval C) against the horst. (c) A dip map at the base of Tier-1 showing concentric PF around the circular pockmark shown in (a). 
(a)

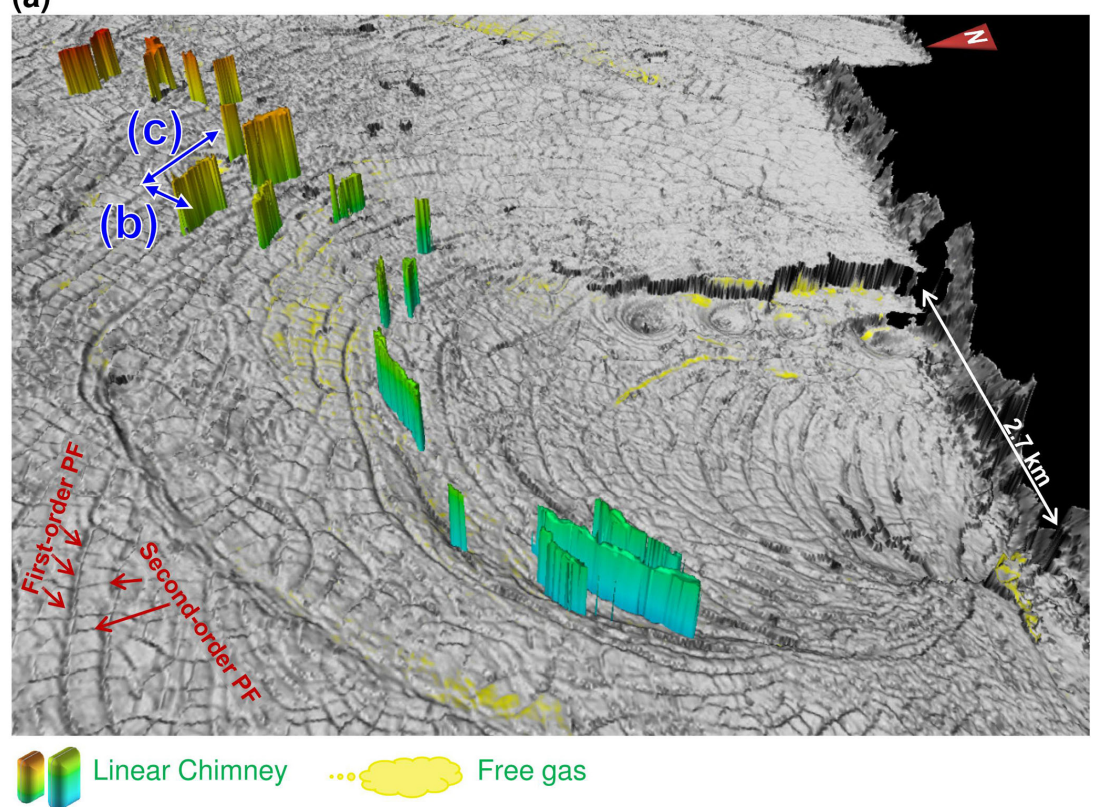

(b)

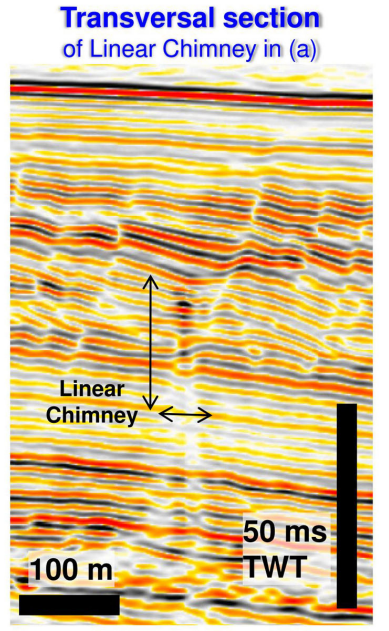

(c)

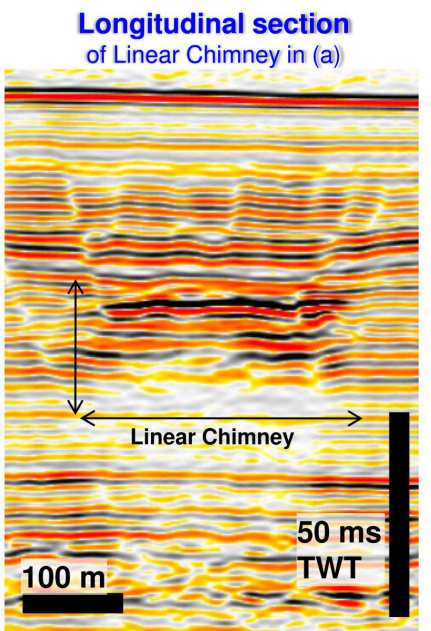

Figure 5. Morphology of Linear Chimneys. (a) 3-D visualisation of Linear Chimneys in Syncline-3 parallel to preferentially and concentrically orientated polygonal faults parallel to syncline edge. The 3-D chimney bodies are issued from the 3-D mapping of the high-amplitude anomaly columns on seismic sections. (b) and (c) show transverse and longitudinal seismic sections through the Linear Chimney in (a).

In the study area chimneys are often associated with highamplitude patches and shallow depressions; all of these pile up to form vertical successions (see Ho et al., 2012a). Linear Chimneys are typically expressed as "squeezed elongate columns" of acoustic distortion zones in seismic data (Fig. 5a); in plan view they appear as linear amplitude anomaly zones tens to hundreds of metres wide with an aspect ratio of 1:4 (Fig. 5a; Ho et al., 2012a). Linear Chimneys may terminate upwards or downwards into NHAA (e.g. Fig. 5b-c) or upward into linear flame-like patterns of PHAA (see seismic section and amplitude map, Fig. 6). They may also terminate upwards into linear, elongate, or sub-circular shallow depressions on the modern seafloor (Fig. 7). These three elements can be combined to form three key variations of vertical stacking sequences (Fig. 8; see also Fig. A3), as described below.

- Type-1 Linear Chimneys terminate upwards into linear PHAAs within depressions, which are shallow and flatbottomed with relief in the range 3-5 ms TWT (Fig. 8). The acoustic columns defining the chimneys are often associated with velocity pull-up effects.

- Type-2 Linear Chimneys terminate upwards into columns of linear NHAAs (Fig. 8). The chimney body is also characterised by push-down reflection zones. 
- Type-3 Linear Chimneys terminate upwards into linear PHAAs with depressions and downwards into linear NHAA columns (Fig. 8). Linear Chimneys of this type are usually not represented by any reflection distortion zone.

The NHAA columns in Type- 2 and Type- 3 are situated in the lower part of the PF tier and are capped by the Intra-Pliocene regional barrier (see seismic lines in Figs. 9 and 10).

The topmost termination of a chimney is easily distinguishable when associated with pockmarks or PHAAs (see Heggland, 1997; Judd and Hovland, 2007; Cathles et al., 2010), whereas identifying the lower termination is challenging due to signal perturbations that increase with depth (Hustoft et al., 2007, 2009). Apart from the downward terminations of Type- 3 chimneys that can be clearly distinguished due to the NHAA column, the other two types are poorly constrained. Hustoft et al. (2007) suggested that the base of the chimney is marked by the disappearance of distorted seismic reflections. In this study, the lower tip of chimneys is considered to be located at the level at which columns of distorted seismic reflections start to branch out in opposite directions or where distortions disappear (Fig. 9a).

\subsubsection{Linear Chimneys and fault patterns}

In the study area, Linear Chimneys mainly occur within the Pliocene PF Tier-2 (Fig. 2b; Ho, 2013), which are parallel to PFs that have preferential directions (Fig. 5a). Both elements are often parallel to adjacent tectonic faults or salt structures (Figs. 1, 9c). Although Linear Chimneys are often parallel to the first-order PFs, some do not show preferred orientations close to the NNE edge of Syncline-2 (Fig. 10a) where concentric and unidirectional $\mathrm{PF}$ arrays intersect. At this location PFs are more isotropically arranged (Fig. 10b). Another exception occurs above Syncline-1, where linear venting structures are parallel to the second-order PFs and the eastern edge of Syncline-1 (Fig. 11).

Few types of gas-charged fluid migration features are found within anisotropic PF networks. In the interval of PF Tier-2 in map view, a kilometric-scale PF area is filled by negative high-amplitude patches in Syncline-3 (Fig. 9b), where NHAA lumps are observed to mimic the PF pattern. The whole NHAA area is limited laterally by the extensional fault of Syncline-3 and vertically by the Intra-Pliocene horizon, below which Linear Chimneys of Type-2 are observed (Fig. 9a).

Linear Chimneys intersect fault planes in different positions within PF Tier-2. A catalogue and statistical analysis comprising counts of each intersection position has been made by examining 209 detected chimneys (Fig. 12; see also Fig. A3; sourced from Ho, 2013; Ho et al., 2016). The Linear Chimneys intersecting PFs can be split into two main populations based on the number of their positions (Fig. 12): (1) the first population $(54 \%)$ has downward terminations intersecting the lower part or basal tips of single or conjugate PFs and rises from the lower footwall of tilted PF blocks or horsts; (2) the second population (19\%) stems from (around) the intersection of pairs of conjugate PFs and occurs along the middle of the PF grabens (hanging wall).

Populations (1) and (2) represent $73 \%$ of the total number of chimneys (see right column in Fig. 8 for summary). In the case of population (2), the Linear Chimneys may also intersect the lower part of the PFs, but the seismic resolution and distortion prevents an accurate determination of their position. Smaller populations include chimneys whose body intersects the middle portion of the PF footwall and hanging wall $(9 \%)$ and chimneys occurring in the middle of PF blocks (7\%). The remaining $10 \%$ of chimneys intersect at other various positions (Figs. 12, A3). Among the $73 \%$ (Fig. 12), $23 \%$ and $8 \%$ of the chimneys terminate downwards into negative bright spots in the PF footwall or hanging wall, respectively; these subpopulations all belong to Type-3 Linear Chimneys. Consequently, one-third of the chimneys are associated with free gas stored in the lower part of PF blocks, while the rest only have apparent roots in the lower part of the PF tier or deeper.

\subsubsection{Radial high-amplitude depression networks along syncline-related faults}

Although most linear venting structures occur in PF Tier2 , some exceptions occur. For example, a radial network of a leakage system at a kilometre-scale was found along syncline-related extensional faults in a deeper Late to Middle Miocene interval devoid of PFs (for details, see Fig. 13). This complex network is composed of interconnected linear depressions associated with PHAAs that overlie a network of big Linear Chimneys (Fig. 13a-b). These Linear Chimneys are characterised by push-downs (Fig. 13c), most of which have horizontal lengths around or in excess of a kilometre with the longest ones occurring along the strike of extensional faults (Fig. 13a).

\section{Interpretations and discussion}

The geometrical coincidence of Linear Chimneys and PFs implies a relationship between these structures. To decipher the genetic relationships the following aspects need to be discussed: (1) the relative timing of PFs and Linear Chimney formations, (2) the gas-charged fluid migration pathways to the nucleated location of chimneys, (3) the mechanisms of preferential gas accumulation, and (4) factors that control the linear planform of the chimneys.

\subsection{Timing of polygonal faulting}

Analysing the timing of polygonal fault formation is essential for the discussion of whether pre-existing PFs affected fluid migration pathways, i.e. chimneys. The relationship between the timing of PFs and Linear Chimney formation can be con- 
(a)

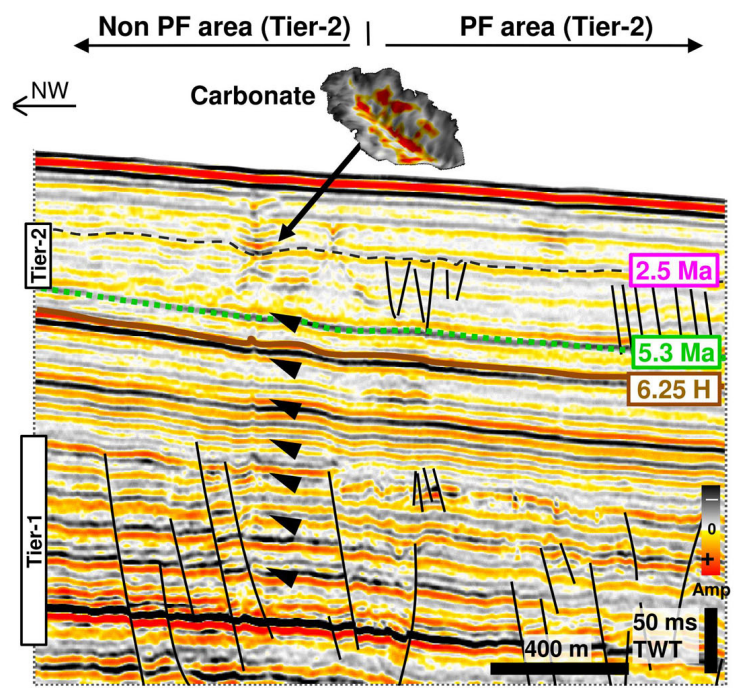

(b)

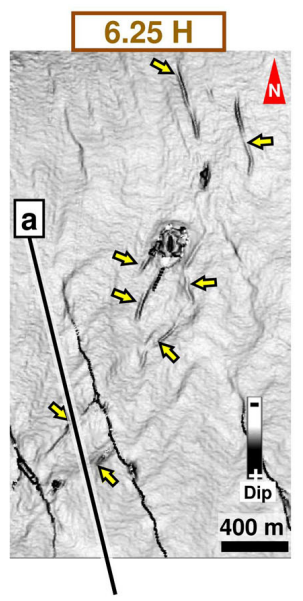

(c)

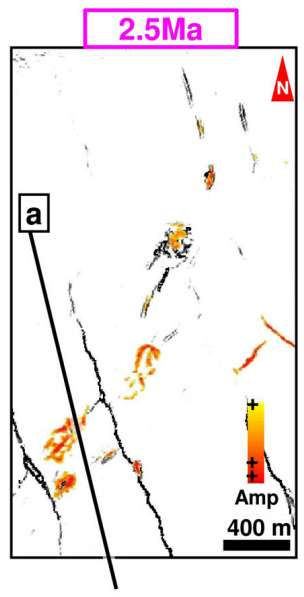

Figure 6. Group of Linear Chimneys with flame-liked PHAAs at upward terminations. (a) Seismic section shows the Linear Chimneys emanating from Tier-1 and terminating upward in the upper Pliocene units. This section is a close-up of the thinning wedge studied in Ho et al. (2013). The full profile is shown in Fig. 3. Line location is shown in (b) and (c). (b) Dip map of horizon $6.25 \mathrm{H}$ showing the linear planform of chimneys (yellow arrows). (c) Isolated, positive, high-amplitude anomalies at the top boundary of Tier-2. They occur at the topmost termination of Linear Chimneys and are interpreted as methane-related carbonates.

(a)

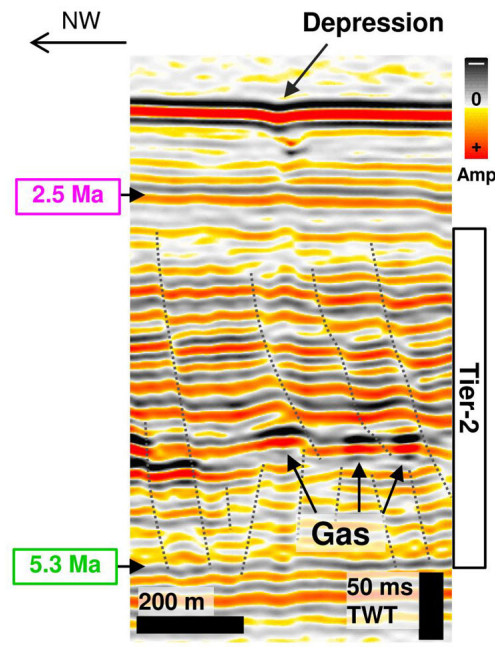

(b)

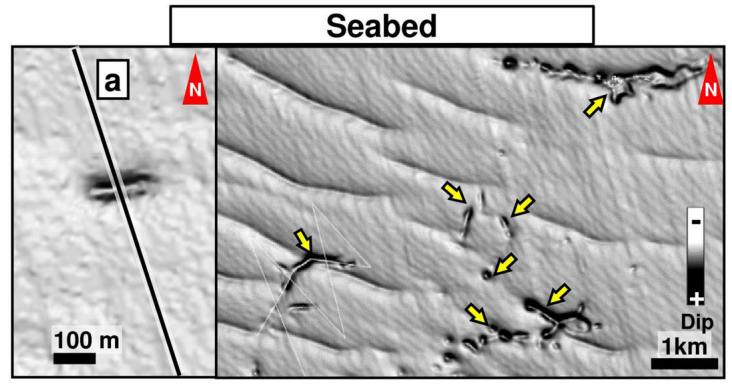

Figure 7. Dip map showing linear depressions at the present day seafloor. (a) Seismic section shown in map (b) is across one depression, which occurs at the topmost termination of a Linear Chimney emanating from Tier-1. (b) The linear depressions at issue are indicated by yellow arrows and locally interfere with regularly spaced furrows likely of sedimentary origin.

strained by several lines of evidence. Polygonal fault nucleation is widely considered to occur during the early stages of fine-grained sediment compaction (see Goulty, 2008). Authors like Berndt et al. (2012), Ostanin et al. (2012), and Carruthers (2012) suggested that PFs formed in shallow subseafloor sediments and ceased propagating when they tip out on the seafloor. Polygonal faults in the Neogene-Quaternary deposits of Lake Superior, Hatton Basin, and Vøring Basin indicate that their growth is very recent and could occur to the present day seafloor (Berkson et al., 1973; Jacobs, 2006; Berndt et al., 2012; Laurent et al., 2012). Recently, Sonnenberg et al. (2016) confirmed that PFs grew close to the seafloor with evidence of fault scarps filled by onlapping synsedimentary strata. The non-uniform topmost terminations of 


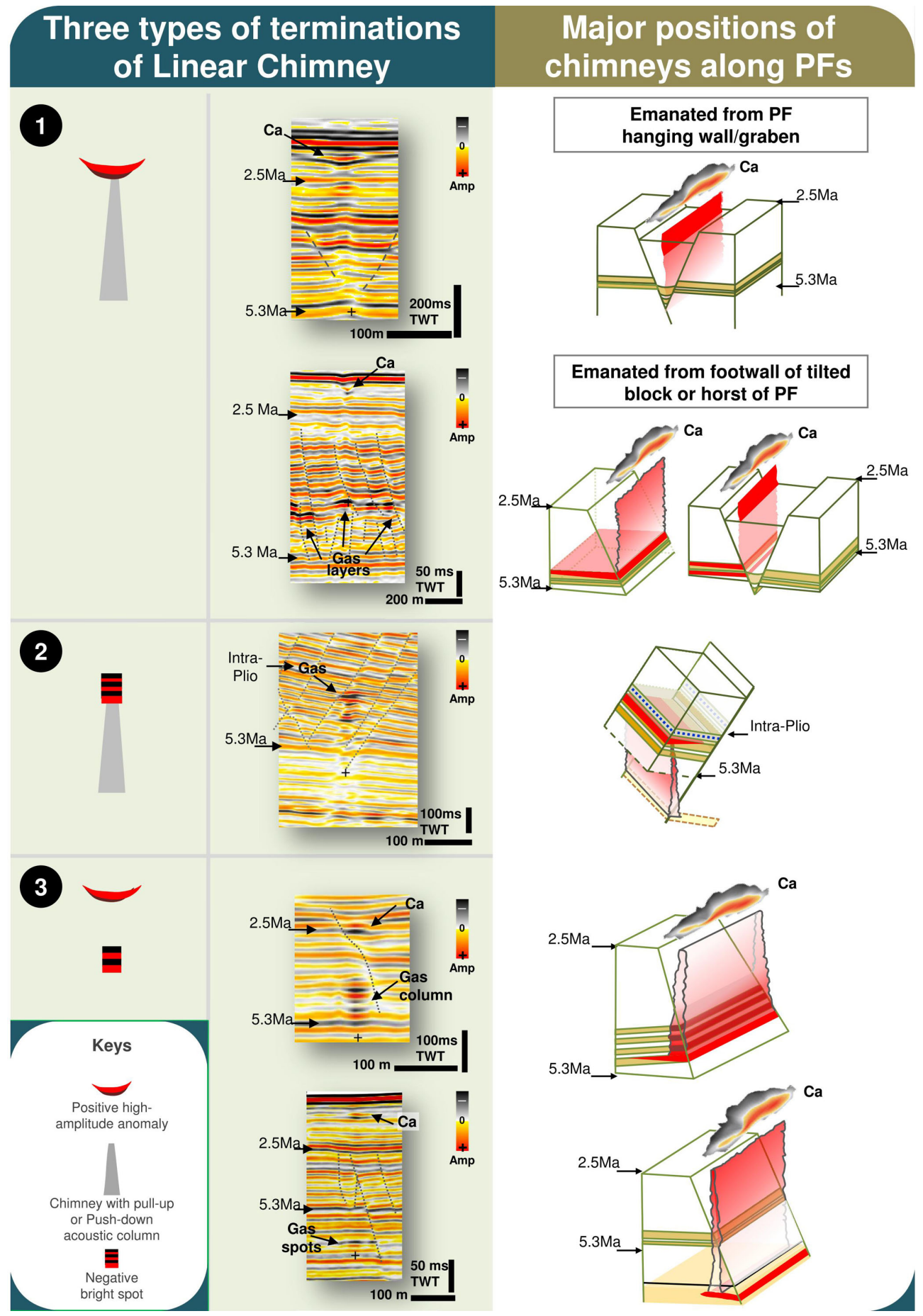

Figure 8. Classification scheme showing types of terminations of Linear Chimneys. Left column: symbols which represent the three groups of Linear Chimneys with different upward and downward terminations. Middle column: the seismic images of the chimneys represented by the symbols. The apparent bases of chimneys are marked with crosses. Right column: the 3-D interpretation of the major intersecting positions between the polygonal faults and the Linear Chimneys shown in the adjacent seismic images.

PFs indicate upward propagation after PF initiation (Berndt et al., 2012).

Within the study area, new evidence supports the general consensus that PFs grew in sediments very close to the palaeo-seafloor. Ho et al. (2013) document that in the synsedimentary growth wedge of Tier-2, buried ca. $50 \mathrm{~ms}$ TWT below the modern seafloor (see Fig. 3; Ho et al., 2013), PFs disappeared progressively as the tier thickness decreased be- 


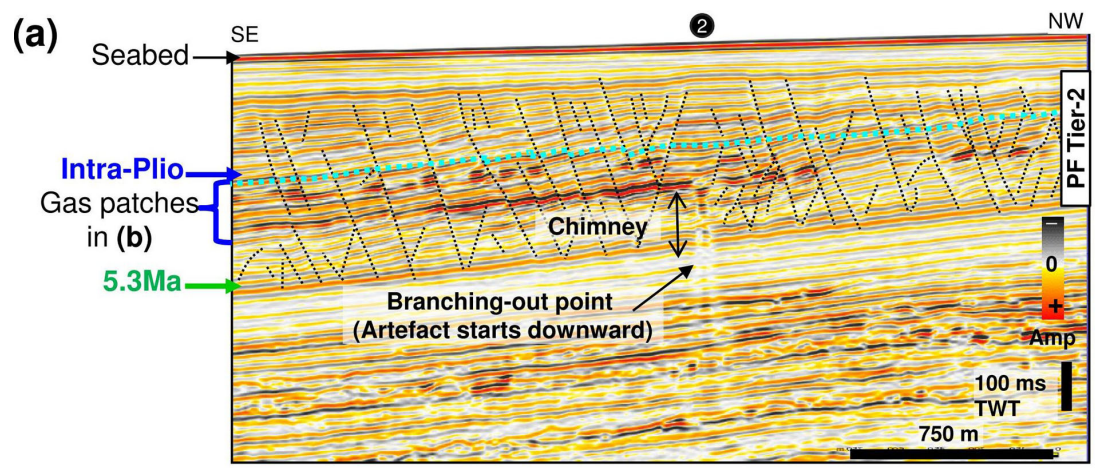

(b)

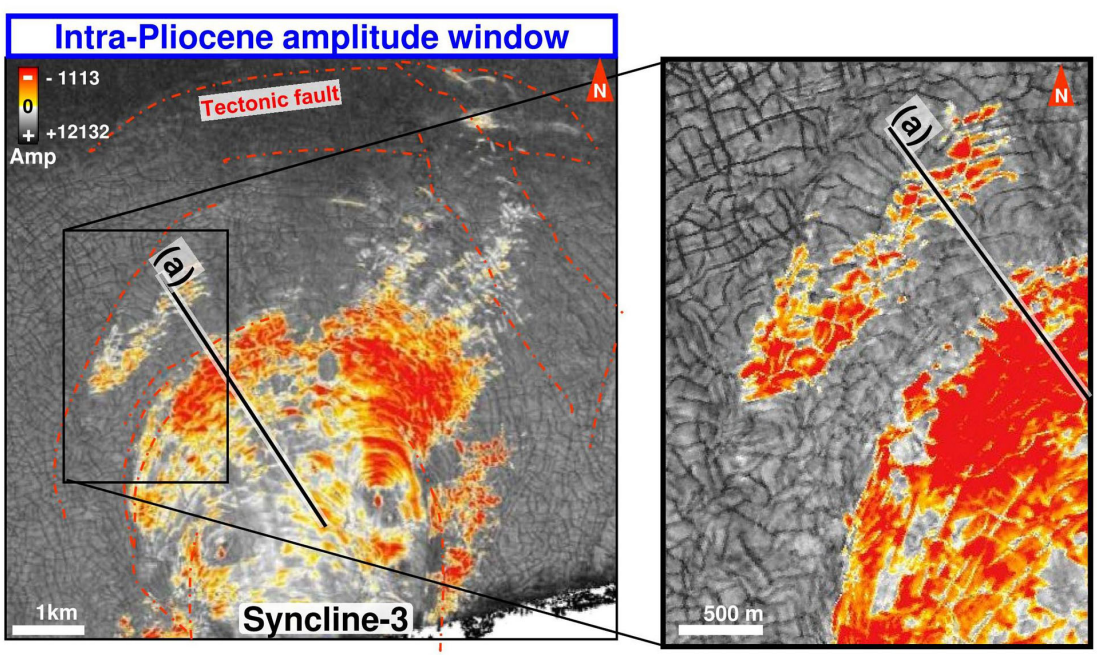

(c)

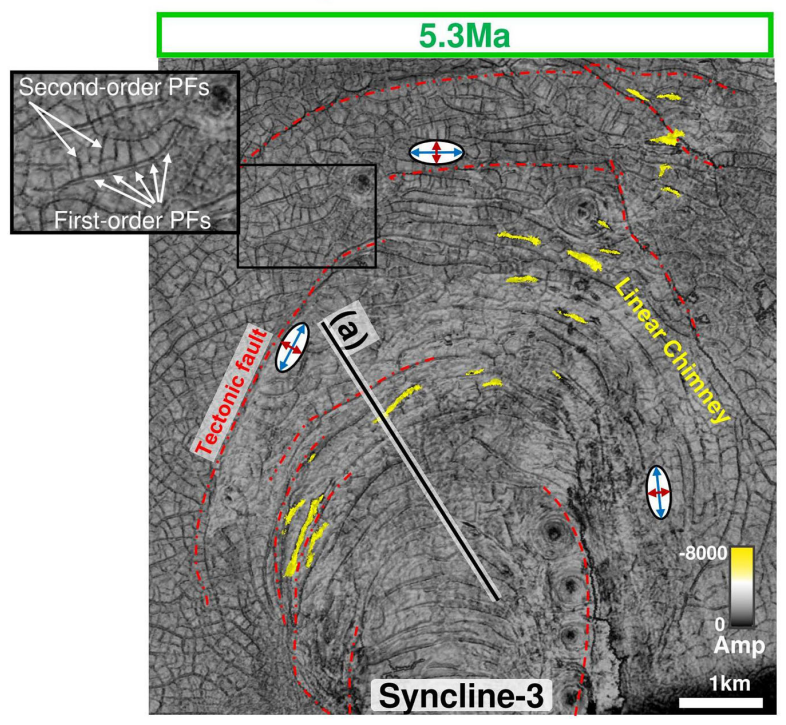

Figure 9. Linear Chimneys of Type-2 and PF cells filled by gas in Syncline-3. (a) Seismic section showing Type-2 Linear Chimneys below gas-filled layers (expressed by negative high-amplitude anomalies) within PF blocks capped by the regional impermeable barrier "IntraPlio". Numbered black-filled circles indicate the type of chimney. Line location shown on maps in (b) and (c). (b) Amplitude extraction of a window in the middle of Tier-2 over Syncline-3 showing gas-filled PF cells forming a kilometre-scale gas accumulation laterally bound by extensional faults. Images sourced from Ho (2013; Ho et al., 2013). (c) Overlay of two amplitude maps shows the distribution of Linear Chimneys along the first-order, anisotropic PFs that are parallel to synclinal tectonic faults (indicated by red dotted lines). The map of a negative high-amplitude reflection within an isolated chimney body (indicated by yellow colour) is superimposed on the amplitude map of horizon 5.3 Ma at the base of PF Tier-2. The blue axis and red axis on stress ellipses indicate the palaeo-orientation of the intermediate and minimum stresses, respectively. 
(a)

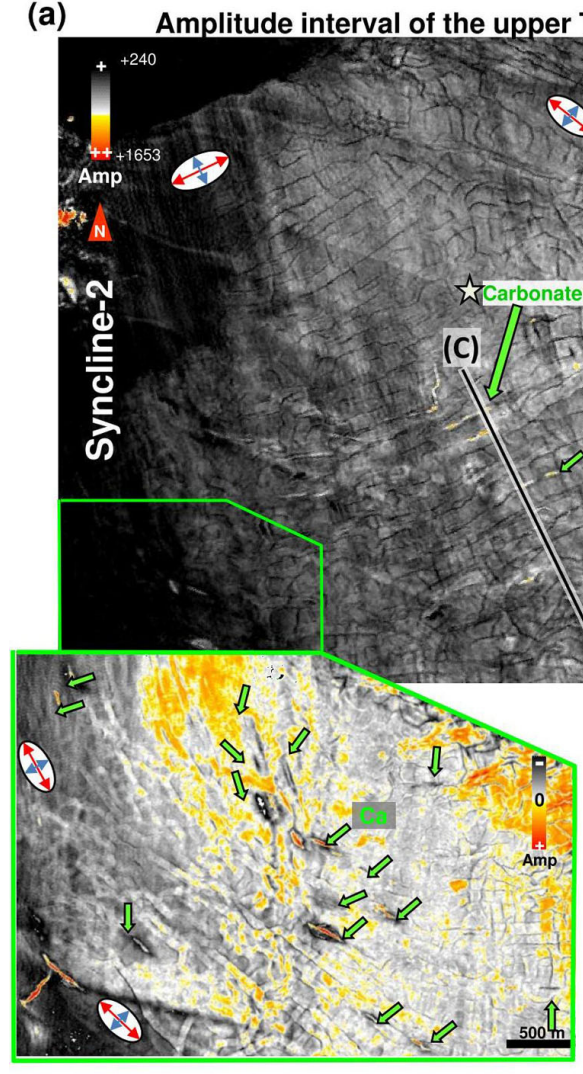

(b)

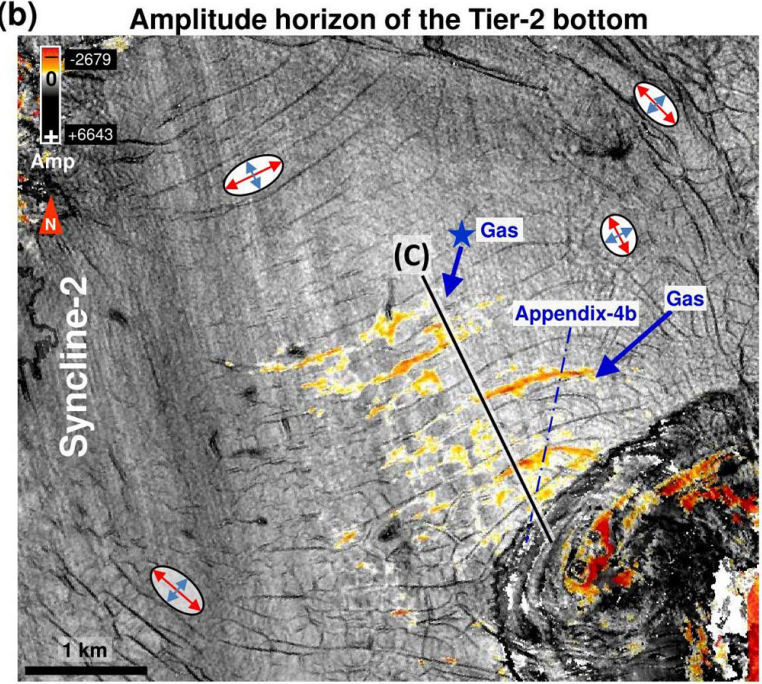

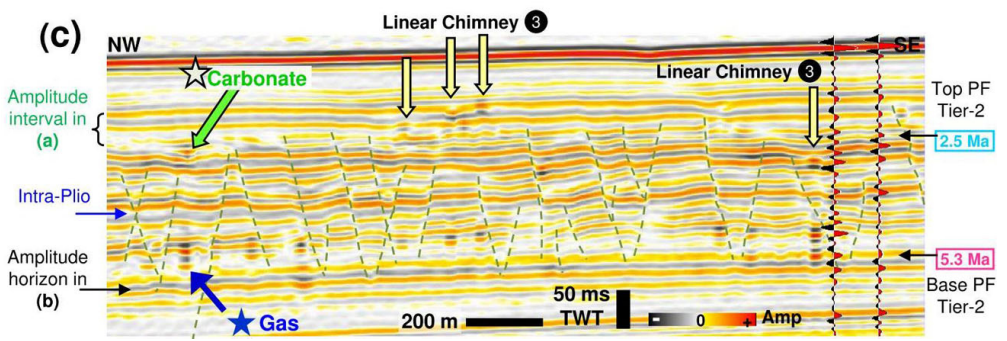

Figure 10. The linear planform of the topmost and lowest termination of chimney Type-3, and the alignment of the Linear Chimneys parallel to polygonal faults in withdrawal Syncline-2. (a) RMS amplitude extraction of a window in the upper portion of PF Tier-2 showing linear carbonates (red: positive high-amplitude anomalies, PHAAs). Exceptional examples of Linear Chimneys without preferential orientation can be observed close to the NE edge of the syncline (see carbonates on the right side of the image). See brackets in (c) for the vertical location. The blue axis and red axis on stress ellipses indicate the palaeo-orientation of the intermediate and minimum stresses, respectively. (b) Amplitude map of horizon at the base of PF Tier-2 showing the linear gas accumulations (red: negative high-amplitude anomalies, NHAAs). Note that NHAAs are aligned parallel to overlying PHAAs shown in (a). (c) Seismic section showing positive bright spots (Ca for carbonate) above and negative bright spots below Linear Chimneys. Numbered black-filled circle indicates the type of chimney. Green arrows indicate the position of carbonates, while yellow ones indicate locations of Linear Chimneys.

low 60 ms TWT towards the pinch-out. This means that PFs started to grow below the seafloor at shallow depth: minimum $60 \mathrm{~ms}$ TWT (faulting during the tier deposition) or maximum $110 \mathrm{~ms}$ TWT (faulting at present day). Similarly, the timing evidence of PF faulting in Tier-1 is shown by onlapping reflections on both sides of a dome underlain by a circular PF-bounded horst (interval C in Fig. 4a; see also 4bc). Knowing that the onlapping strata are located $80 \mathrm{~ms}$ TWT above Tier-1, this dates the latest activity of the PFs subsequent to Tier-1 deposition. It can be observed that the particular PFs bounding the circular horst are significantly longer than most other PFs and propagate largely above Tier-1 (into interval A in Fig. 4a). Thus, it is likely that most PFs formed during Tier-1 deposition, and some were reactivated once after the tier was buried (below interval A) at shallow depth (15 ms TWT below the seafloor). To conclude, based on the literature and our seismic observations, the topmost bound- ary of both PF tiers represents the approximate timeline of when the main tier ceased to form.

\subsection{Formation of Linear Chimneys}

Seismically recorded "gas chimneys" are commonly considered to be the result of hydraulic fracturing of an impermeable interval (Pyrak-Nolte, 1996; Heggland, 2005; Løseth et al., 2011; Hustoft et al., 2007, 2010; Cevatoglu et al., 2015). Hydraulic fractures develop when pore pressure exceeds the sum of the minimum lateral stress and the tensile strength of the sediment above and propagate upwards perpendicular to the direction of the minimum lateral stress (Phillips, 1972; Cosgrove, 1995; Hustoft et al., 2010; Løseth et al., 2009, 2011). Because the geological significance of chimneys has already been well discussed in many previous studies (see Løseth et al., 2001; Berndt et al., 2003; Hustoft et al., 2010; 


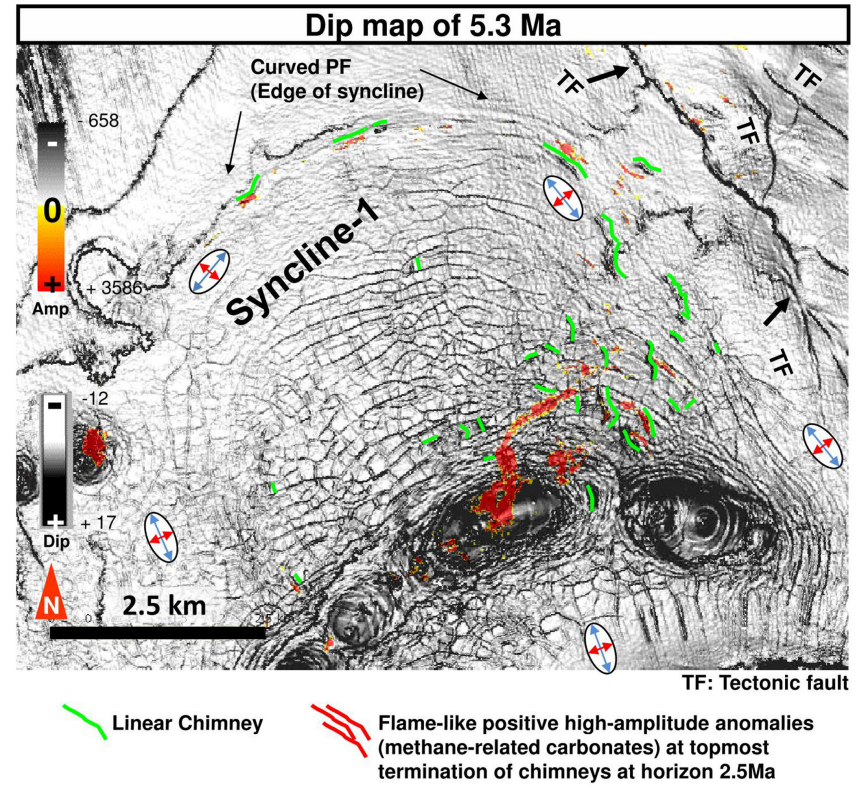

Figure 11. Dip map of key horizon 5.3 Ma (base of PF Tier-2) showing the distribution of Linear Chimneys in Syncline-1. Isolated positive high-amplitude anomalies (PHAAs) at the topmost terminations of Linear Chimneys at horizon $2.5 \mathrm{Ma}$ (interpreted as methane-related carbonates) are superimposed on the dip map. Green lines highlight the locations of Linear Chimneys underlying the carbonate. Red amplitudes are flame-like PHAAs. The blue axis and red axis on stress ellipses indicate the palaeo-orientation of the intermediate and minimum stresses, respectively.

Plaza-Faverola et al., 2010; Ho et al., 2016), we focus here on their timing and geometrical development in interaction with PFs.

\subsubsection{Timing of chimney formation related to PFs}

The timing of chimney formation is suggested to be recorded by their associated pockmarks/depressions, and methanerelated carbonates, which formed at a chimney's topmost terminations when hydrocarbon-charged fluid reached the palaeo-seafloor. Chimneys connected to pockmarks have been suggested to have formed during catastrophic blowout events on the seafloor (Judd and Hovland, 2007; Hustoft et al., 2010). An analogue of a modern outcrop was observed when a pockmark $40 \mathrm{~m}$ in diameter and $7 \mathrm{~m}$ deep formed above a chimney while overpressured water was expulsed after $51 / 2$ months from a deeper reservoir (Løseth et al., 2011). During an experiment on $\mathrm{CO}_{2}$ injection in reservoirs, a $10 \mathrm{~m}$ long chimney terminating in a $4.5 \mathrm{~m}$ wide and $6 \mathrm{~m}$ deep pockmark on the seafloor developed within $48 \mathrm{~h}$ at an onshore test site in Scotland (Cevatoglu et al., 2015). These studies demonstrate that chimneys terminating into pockmarks or depressions can form within days. Similarly, PHAAs at the top of chimneys, interpreted as methane-related carbonates (Hustoft et al., 2007; Petersen,
2010; Plaza-Faverola et al., 2011; Ho et al., 2012a), usually precipitate less than a metre below the seafloor (Regnier et al., 2011) and can be considered as a time marker for gas migration through chimneys to attain the palaeoseafloor. Because PHAAs and the associated chimneys extend exactly from the linear gas accumulation below (see upward and downward terminations of Type- 3 chimney in maps; Fig. 10a-b) and because the gas accumulations are compartmentalised by the anisotropic PF cells and respect the planform of PF cells (see Fig. 10c), the PF networks must have formed prior to the gas accumulations and hence modulate the planform development of chimneys and the subsequent fluid features.

It could be argued that the chimneys emanating from the lower part of a polygonal fault plane formed by overpressured gas expulsion at the upper tip of proto-PFs, which were still in their developmental stage. This assumption is, however, inconsistent with the fact that many chimneys are modern and currently active as indicated by PHAAs and pockmarks at their topmost terminations on the present day seafloor (Fig. 7), while the fault planes have already fully developed since the end of the Pliocene. The nucleation point of the chimneys must therefore correspond to a level from which the fluid could not migrate further along the fault plane, and hence it forced the gas to open a new migration path, i.e. chimney.

\subsubsection{Levels of chimney nucleation and locations of multi-layered gas reservoirs within PF tier}

As the nucleation site of Linear Chimneys is directly linked to the site of gas accumulations, we first investigate the stratigraphic location of gas accumulations by tracing the gas migration pathway prior to the accumulations. This is done by analysing the chimney's downward terminations. Type3 chimneys (31\%) initiated within the PF tier as indicated by negative high-amplitude columns at their downward termination (Fig. 10c), which are interpreted as residual gas accumulation. In contrast, the downward terminations of the major population of chimneys (Type-1) cannot be determined with precision because of signal attenuation downward. However, they still appear to root in the lower part of the tier or its base, suggesting that overpressured gas-charged fluids occurred around the lower boundary of the tier, which most probably leaked and emptied the reservoirs, leaving no or only weak seismic signals. Therefore, Type- 3 chimneys are interpreted as an earlier stage of Type-1, before their gas was exhausted.

Now we investigate how gas migrated specifically into the lower part of the PF tier or below. Because PFs root at different depth levels and the presence of bright spots occurs at different strata (within or below the lower fault tier) (see the profiles in Fig. A4), it is suggested that gas below the PF tier migrates via the long roots of PFs into different perme- 


\section{Percentages of chimney-PF intersecting position (209 measurements)}

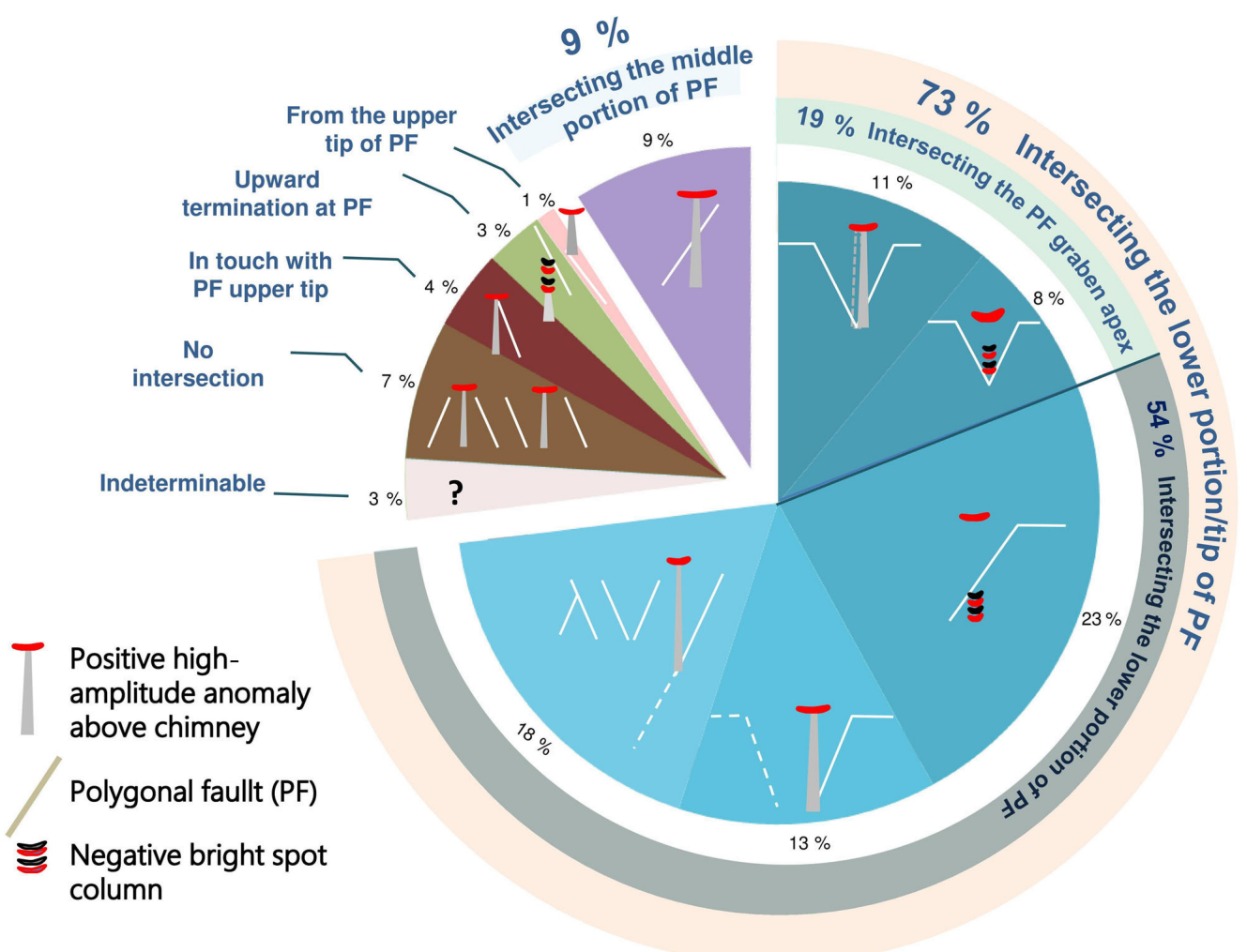

Figure 12. Pie charts showing the percentage of chimneys intersecting or emanating from different parts of fault planes or adjacent fault blocks. The position of the chimney-fault intersections are illustrated with cartoons in each pie segment. See key at bottom left for drawing codes. Image modified from Ho (2013).

(a)

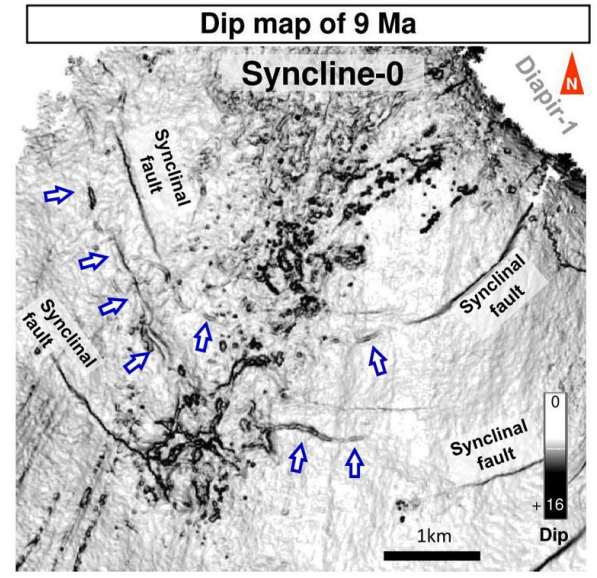

(b)

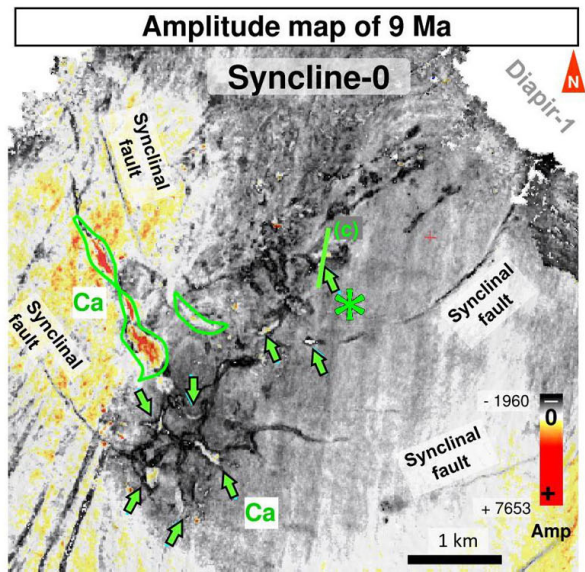

(c)

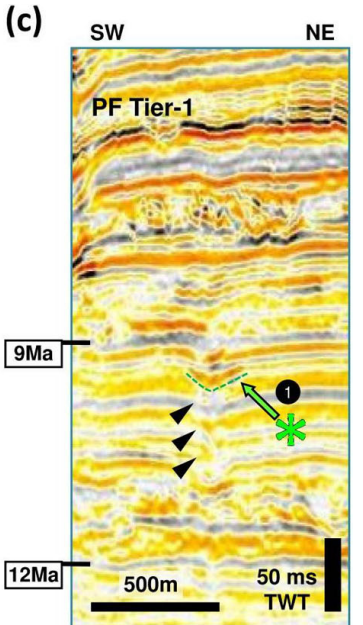

Figure 13. Kilometre-scale Linear Chimneys along the tectonic faults of Syncline-0. (a) Dip map and (b) amplitude map of horizon 9 Ma showing the geometry of a radial network of positive high-amplitude depressions that overlays a big Linear Chimney network. Green star locates the PHAA depression shown in (c). (c) Zoom of seismic profile in Fig. 2b showing a PHAA within the radial network overlying a chimney. Black arrows indicate the chimney. Numbered black-filled circle indicates the type of chimney. See green dotted line in (b) for location. 
able layers within the tier and forms multi-layered reservoirs (Fig. 9a).

We do not rule out the possibility that gas was already present within the carrier bed before polygonal faulting. However, the seismic data clearly show that the timing of tectonic faults and PF overlapped (Fig. A4a). In many cases tectonic faults (propagation) post-date PF initiation or formation, and it has been demonstrated that tectonic faults are the main fluid migration paths for fluid into the shallow interval in the study area (Imbert et al., 2017; Ho, 2013). The traps within the PF tier are small and would not take much time to charge. Gas migration can occur quickly and the chimneys or seep carbonates record the very recent phases (end of the Pliocene) of overpressure within the tier. If hydrocarbon was present in the carrier bed prior to polygonal faulting the succession of shale above PFs would be very thin (significantly $>200 \mathrm{~m}$ ). It is unlikely that this thin succession of shale would have enough seal integrity. It is more likely that the seal formed after PFs when the overburden was thicker and more compacted.

As the exact stratigraphic levels of gas sources and migration pathways to the base of chimneys cannot be identified, based on the region in which chimneys are rooted, we propose the following scenarios when gas migrated upwards from deeper sources: (1) gas was trapped in strata along sealed tectonic faults below the PF tier; (2) gas migrated laterally, reached carrier beds immediately below the PF tier, and was intersected by long PFs, then accumulated there (Figs. 14a, A4); or (3) gas migrated along the lower portion of the PFs to reach permeable layers inside the lower tier (Fig. 14b). These three processes either happened solely or in combination with each other as a series of steps.

In conclusion, the rooting position of the majority of chimneys suggests that, before the chimney nucleated, gas migrated to and accumulated preferentially in the lower part of or at the base of the PF tier.

\subsubsection{Mechanism of gas trapping in the lower part of the PF tier}

As supported by the statistical analysis presented herein, over $54 \%$ of chimneys stem from the region around the lower PF footwall; therefore, we infer that over $54 \%$ of the time gas accumulated in the footwall at the base of chimneys. It is also the same for the $19 \%$ of chimneys that stem from the lower PF grabens (hanging wall). As a result, $73 \%$ of the total time gas preferentially accumulated in the lower part of PF blocks, so we investigate the cause of this phenomenon. We suggest that two hypotheses in combination account for the mechanism of preferential gas accumulation in the lower PF footwalls of tilted blocks, horsts, and lower hanging walls/grabens: (a) the presence of an impermeable regional seal and (b) an impermeable portion of fault plane). Two other hypotheses together determine the preferential gas migration to the lower PF footwall: (c) the differential strain in fault blocks and (d) the stratigraphic position of permeable layers in fault blocks. Finally, one hypothesis is for the graben hanging wall: (e) the increase in local permeability.

a. Impermeable barrier. The seismic record documents the fact that gas is present in the lower part of PF Tier-2 over a vast area, below the regional impermeable IntraPliocene barrier (Ho, 2013). The Intra-Pliocene barrier corresponds to the topmost boundary of free gas accumulations and does not parallel the seafloor (blue dotted line in Fig. 9a). As a result, this impermeable barrier likely does not represent bottom-simulating reflectors (BSR) and is hence interpreted as of purely depositional origin.

b. Fault seal. Persistent occurrences of gas accumulations in the lower part of the PF tier below the impermeable barrier, regardless of faulting offsetting it, likely indicate that the lower portion of PF plane is not hydraulically communicated with the upper one. Otherwise gas would use the upper fault plane to migrate further to the upper fault tier (Ho et al., 2016; Ho, 2013). Therefore, the upper portion of the PF fault plane above the regional impermeable barrier is likely impermeable, at least during gas migrations (Ho et al., 2016), and the downward limits of the impermeable fault zones are possibly non-uniform and can vary or extend beneath the Intra-Pliocene barrier. This hypothesis is well demonstrated, for example, by the vast distribution of gas-filled PF blocks below the Intra-Pliocene barrier in Syncline-3 (Fig. 9a).

It can be argued that sediments in the lower PF tier are more permeable and lead gas to preferentially accumulate in such a place. This possibility is disregarded because of the similarity between the lithologies in the upper and lower part of the PF tier as indicated by Total S.A. internal well reports, although it is noted that the permeability measurement of the host sediments is unavailable.

c. Differential strain. Shear strain resulting from extension and normal faulting affects the hydraulic properties of rocks adjacent to the fault surface (Barnett et al., 1987). Extensional faulting induces significant shear strain and dilatancy (Zhang et al., 2009), which consequently enhances the porosity and permeability of the wall rocks in shallow buried depths (Barnett et al., 1987). Numerical modelling demonstrates that the lowest shear stresses occur in the footwall block near the basal tip of a normal fault and that the greatest shear stresses occur in the upper part of hanging wall blocks (Fig. 15a; Zhang et al., 2009; Welch et al., 2009). These results match the conceptual model of Barnett et al. (1987) for unlithified shallow buried sediments, which shows that the lower parts of footwalls and the upper part of hanging walls are in a state of compressional strain compared to 
(a)

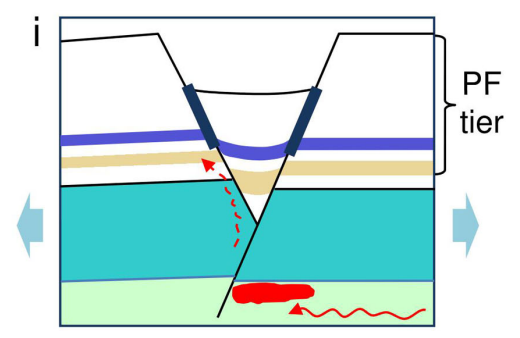

(b)

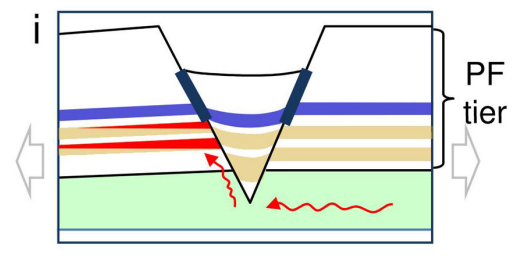

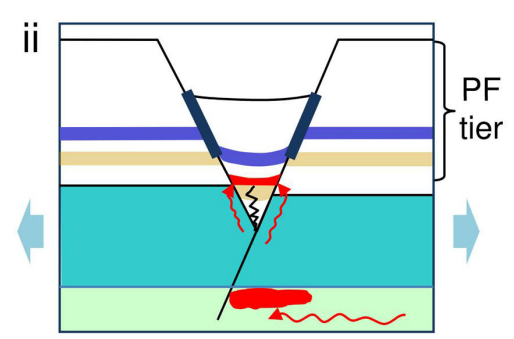

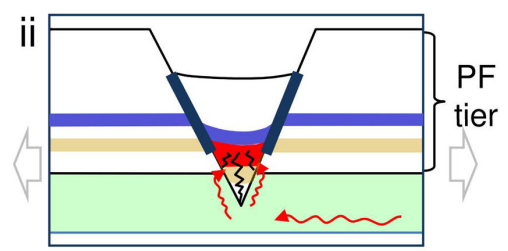

(Cartoon not to scale)

Impermeable barrier $\quad$ Carrier bed in hemipelagites
Permeable layer

Figure 14. Conceptual model for free gas migration into the (multiple) permeable layer(s) in the lower part of PF Tier-2 from an underlying carrier bed. Bold black lines denote the segments of PFs interpreted as impermeable. Cartoon not to scale. (a) Case in which the carrier bed occurs beneath the basal tier surface of the PF tier (the carrier bed thickness can extend beyond the bottom of the cartoon). First-order PFs have propagated beneath the regional tier surface and intersected the carrier bed. (i) Further gas migration into the permeable layer of the footwall and (ii) into the hanging wall. Gas migration into the hanging wall apex is likely because of the increase in permeability induced by apex damaging. (b) Cases in which the carrier bed occurs at the base of a polygonal fault tier. (i) Gas migration into the permeable layers in the footwall via the permeable portion of the polygonal fault plane. (ii) Gas migrates directly into the overlying permeable layer in the fractured hanging wall when it is juxtaposed against the carrier bed.

the top of the footwall and base of the hanging wall in shallow depths (Fig. 15b). As Tier-2 was buried only a few tens of metres when PFs formed, it was very likely not lithified and the lower part of the footwall blocks could have experienced dilatation (Barnett et al., 1987). Therefore, the highest permeabilities would be expected to occur in the footwall of a normal fault near the basal fault tip where gas accumulation is expected to occur. In fact, the majority of Linear Chimneys emanate from the lower parts of the footwall, where gas columns (NHAA) are observed (Fig. 10c).

d. Stratigraphy high. Another explanation for the preferential accumulation of gas in the footwall blocks of the faults is purely geometric: with normal faults, the footwall block is upthrown with respect to the hanging wall, and its series usually raise or tilt upward along the fault (Fig. 15c). As a result, upward migration of gas tends to fill the footwall side of the faults.

e. Fractures increase permeability. For the second major population of chimneys (19\%) that stemmed from the middle of grabens (PF hanging wall), it is likely that the outbreak point of overpressured fluid was located in the lower part of the graben. In the hanging wall, deposits are likely under a compressional regime (Barnett et al., 1987; Welch et al., 2009). Thus, gas will not preferentially migrate into such a location; however, a controlling factor is needed to guide the direction of gas migration. Fracturing in the bottom of grabens leads to an increase in permeability, facilitating the trapping of gas (Fig. 14bii; Ho et al., 2016). This phenomenon happens when graben sediment moves downward along curved, steepening upward faults during extensional faulting (Cloos, 1868; Fossen and Rørnes, 1996; Bose and Mitra, 2010). Alternatively, the lower parts of the graben are subjected to compression where a compressional fold forms a structural trap.

The combination of the above elements is suggested to induce the formation of PF fault-bound traps in the lower part of a PF tier. 
(a)

Numerical modelling of displacement of a normal fault by Welch et al. (2009)

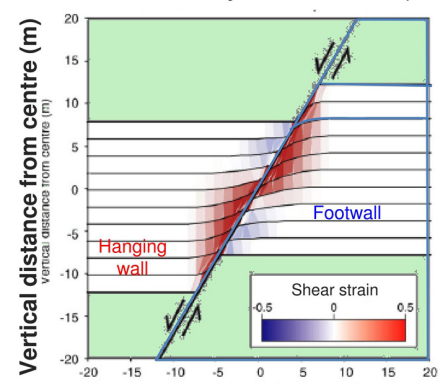

Horizontal distance from centre (m)
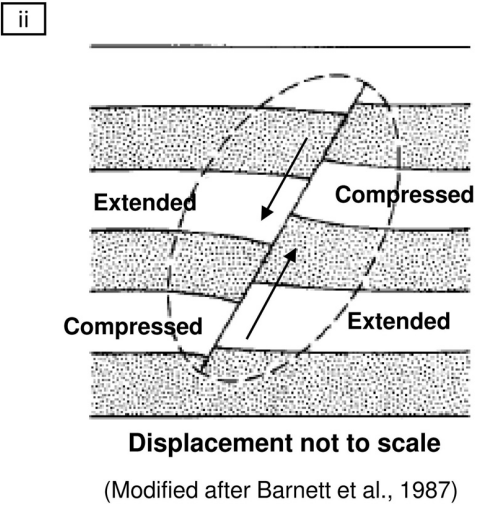

(c)

Higher stratigraphic position

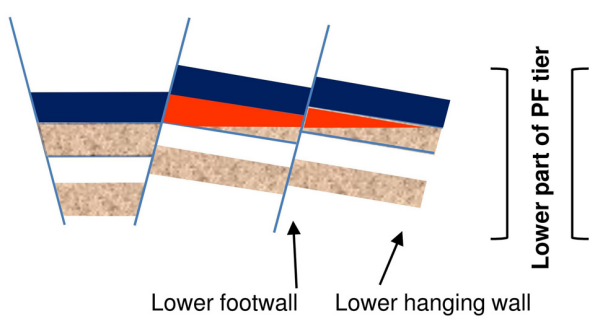

(b) Impermeable barrier

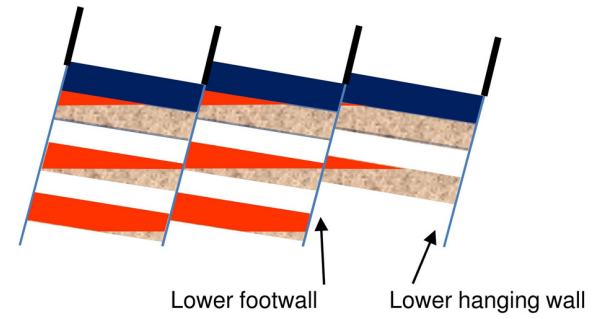

Impermeable

portion of fault

Figure 15. Causes of gas retention within the lower part of PF blocks. (a) Stress distribution around a normal fault. (i) Magnitude of shear strain around a normal fault (modified after Welch et al, 2009). (ii) Displacement of horizontal beds by a normal fault and regions of relative extension and compression in the vicinity of a normal fault in shallow unlithified sediments (modified after Barnett et al., 1987). (b) A higher stratigraphic position of permeable layers in PF footwalls (compared to hanging wall) leads to preferential gas accumulation in such locations. (c) A sufficiently impermeable barrier in the middle of the PF tier prevents further upward migration of free gas.

\subsubsection{Nucleation of Linear Chimneys}

A conceptual model for the formation of Linear Chimneys is proposed below. The majority of Linear Chimneys stem along the surface of the lower PF footwalls at various positions (Fig. 12), suggesting that gas-charged fluids could not migrate along the upper portion of PFs while impermeable (at the moment when chimneys formed). The permeability of small faults in fine-grained marine sediments varies upon changes in stress and the resultant strain around faults (see the laboratory experience of Kaproth et al., 2016), which can likely explain the impermeability along the upper part of PFs. In the literature, numerical models of Nunn (2003) show that fluid pressure might not be high enough to maintain low effective stress in the upper fault zones. Therefore, the upper part of the fault remains closed. Other modelling results show that it is possible for the lower part of PFs to appear permeable and critically stressed in the contemporary stress field, while the upper parts are neither permeable nor critically stressed (Wiprut and Zoback, 2000; Zoback, 2007). In the anisotropic stress area (salt tectonic area), stress generated by the overpressured fluid in host rocks leads to the propagation of planar fractures in PF hanging walls; this likely indicates that fluid pressure was not high enough to open the upper fault plane, but only high enough to overcome the minimum horizontal stress plus the fracture strength of the fault blocks (Delaney et al., 1986; Kattenhorn et al., 2000). Therefore, once the gas trapped in the lower part of the footwalls becomes overpressured (Fig. 16a-b), hydraulic fractures propagate from the footwall to pierce the overlying strata and 
breach the impermeable barrier; as a result, the chimneys were initiated and originated along the lower part of polygonal fault planes.

We would like to emphasise that apart from overpressured fluid (gas) creating new fractures, overpressured gas may also pass through, filling pre-existing sub-vertical cracks/fractures in the hanging wall bottoms along the main fault surface (Fig. 2 in Gaffney et al., 2007, see Supplement). Pre-existing vertical fractures in hanging walls originating from the movements of normal faults have been previously demonstrated by analogue models of van Gent et al. (2010). Fluids may open and extend pre-existing sub-vertical cracks/fractures in the hanging wall only if the pressure required for the fluid entering the hanging wall fractures is less than the one for creating a new fracture (Gaffney et al., 2007). Pore pressures in the PF-bound traps decrease after the fractures propagate or extend, and the residual gas in the traps may re-equilibrate with lithostatic pressure (Zoback, 2007). Consequently, some free gas can remain in the lower part of the PFs at the downward termination of Linear Chimneys (Fig. 10c).

For chimneys originating within the lower part of PF grabens, gas might be compartmentalised in the damaged graben by the impermeable portion of the PF, which was likely extended downward beneath the Intra-Pliocene barrier; therefore, gas was not able to flow into the adjacent horsts (Fig. 14bii). Consequently, hydraulic fractures initiated in the graben centre and propagated upward along the central axis (Fig. 16c).

For chimneys that do not intersect with any fault, i.e. occurring in the middle of PF fault blocks, the illustrated model by Løseth et al. (2009) can be used as a referential analogue (see Fig. 21 in Løseth et al., 2009); a lateral contact point between the edge of the gas accumulation and the upper limit of the tilted storage layer, in the middle of the tilted block, formed a hydrocarbon spill point from which gas chimney nucleated and propagated upward (Løseth et al., 2009). This type of spill point commonly occurs in structural traps.

\subsubsection{Results of chimney linear planform geometry relating to fault orientation}

The linear planform of chimneys and their evident spatial relationship to anisotropic polygonal faults suggest that gas migration and hydraulic fracture propagation are controlled by the alignments of anisotropic PFs. Anisotropic PFs follow the orientations of salt tectonic structures, indicating that the PFs are heavily influenced by the stress states resulting from salt activities (Carruthers, 2012). The presence of faults can perturb the surrounding stress field and affect the adjacent fracture propagation (Rawnsley et al., 1992; Kattenhorn et al., 2000). Thus, degree of horizontal stress anisotropy and the dominant direction of horizontal intermediate stress play a determinant role in both the formation and geometry of anisotropic PFs and hence the planforms of chimneys.
In Syncline-0 polygonal faults are absent, yet the kilometric-scale Linear Chimneys are still present (Fig. 13a). Here, Linear Chimneys are parallel to deep-seated tectonic faults resulting from salt movement, and the horizontal stresses are not equal as the intermediate principal stress exceeds the minimum one (Cosgrove, 1995). The gas pressure was likely not strong enough to overcome the intermediate stress so the hydraulic fractures opened in parallel with it and against the direction of the minimum horizontal stress (Cosgrove, 1995). As a result, the final chimneys are linear in planform and follow the strike of adjacent faults. This example clearly demonstrates that chimneys propagate towards the direction that resulted from the perturbation of horizontal anisotropic stresses induced by the tectonic faults (see Nakamura, 1977).

In the smaller scale of polygonal faulted blocks, Linear Chimneys and anisotropic PFs are often aligned, such as in Syncline-2 and -3 (Figs. 10a, 9c, 5). However, in a particular location above the ridge of Syncline-2, Linear Chimneys are aligned with a pseudo-isotropic (less anisotropic) PF network enclosed in a zone between two (strong) anisotropic PF patterns; one is parallel to the edge of Syncline- 2 and the other has a ladder-like pattern in the centre of Syncline-2 (Fig. 10a-b). In this specific location, although the PF pattern is similar to isotropic polygonal faulted areas the stress magnitude remains greater because of the tectonic extension (Carruthers, 2012). In such an enclosed pseudo-isotropic PF area, chimneys are still linear and all aligned parallel to their rooted PF and do not show strong preferred orientation (Fig. 10a); this particular example leads us to conclude that at tier-fault scale, the in situ anisotropic stress of the nearest PFs has a more significant influence on the orientation of Linear Chimneys than the local tectonic fault stress field. Nevertheless, as the majority of Linear Chimneys are aligned parallel to both tectonic and polygonal faults, Linear Chimneys do not occur in areas where classical isotropic PFs are solely present; therefore, the combination of both anisotropic stress fields of tectonic and polygonal faults is suggested to be the main cause of linear planform chimneys with preferential orientations.

Finally, the lateral propagations of kilometric-scale Linear Chimneys rarely impeded by faults are oriented roughly parallel to them and the chimneys can reach much greater lengths (Fig. 13). In contrast, chimneys within polygonally faulted areas are much shorter horizontally (>300 m) (Fig. A3). This is because the distance for which hydraulic fractures can propagate laterally along a specific trajectory is limited by faults.

In conclusion, the examples above demonstrate that (1) when tectonic faults are solely presented (without PFs) the planform and orientation of chimneys are affected only by the stress field of tectonic faults; (2) while in areas where PFs occur, tectonic stress controls the orientation of anisotropic PFs, and the in situ stress of the PFs controls the orientation of Linear Chimneys. 


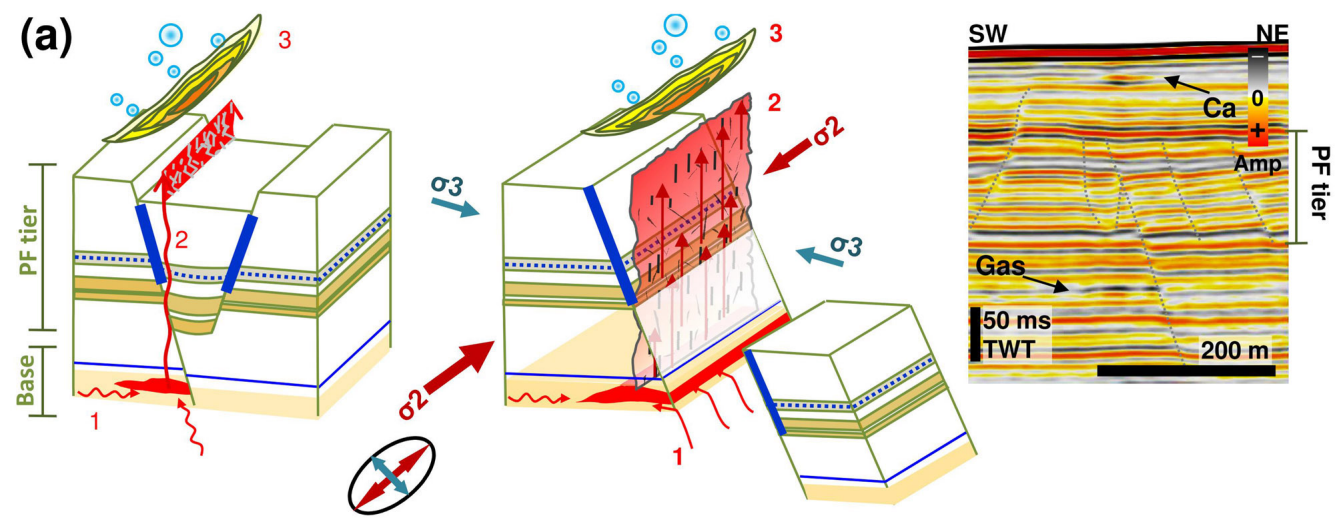

(b)
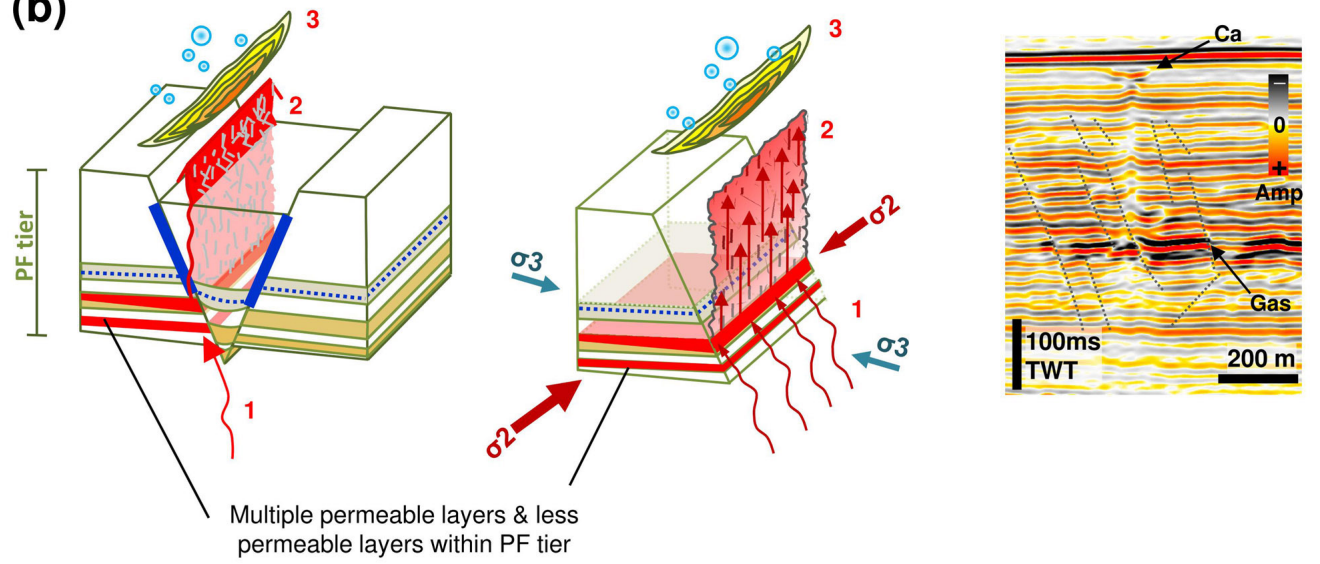

(c)

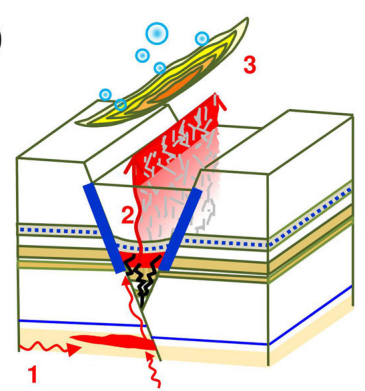

(Cartoon not to scale)
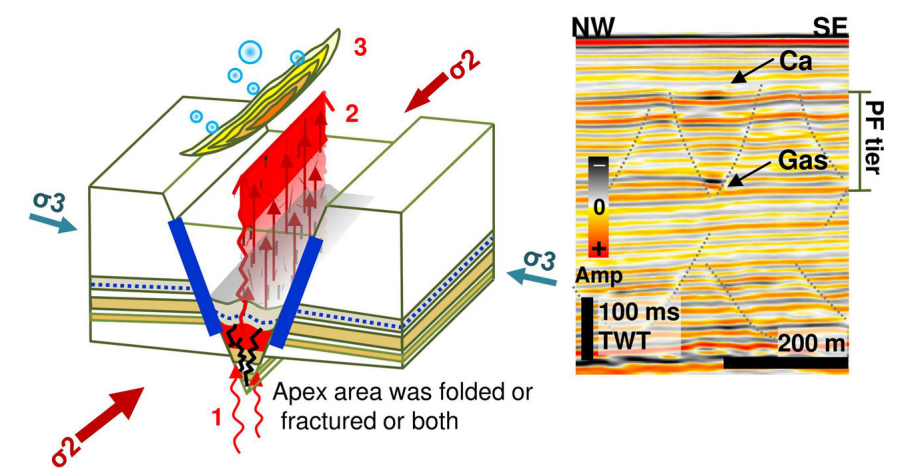

\begin{tabular}{|c|c|c|c|c|}
\hline $\begin{array}{l}\text { Linear gas } \\
\text { chimneys } \\
\text { (vertical) }\end{array}$ & $\begin{array}{l}\text { Permeable fluid paths } \\
\text { in lower portions of } \\
\text { tiered faults }\end{array}$ & $\begin{array}{l}\text { Free gas } \\
\text { accumulation } \\
\text { (NHAA) }\end{array}$ & ..... Intra-Pliocene & $\begin{array}{l}\text { Impermeable } \\
\text { barriers }\end{array}$ \\
\hline $\begin{array}{l}\text { Carrier bed } \\
\text { below PF tier }\end{array}$ & $\begin{array}{l}\text { Multiple permeable } \\
\text { layers (simplified) }\end{array}$ & $\begin{array}{l}\text { Rock with low } \\
\text { permeability }\end{array}$ & S Damage zone & $\begin{array}{l}\text { Methane-related } \\
\text { carbonates in linear } \\
\text { depression (PHAA) }\end{array}$ \\
\hline
\end{tabular}

Figure 16. Left column: conceptual models illustrating alternative gas migration pathways through the PF tier. Right column: seismic lines showing the critical observations. Free gas on seismic profiles is expressed by negative high-amplitude anomaly (NHAA), while methanerelated carbonates are expressed by positive high-amplitude anomaly (PHAA). (a) Below the PF tier from which Linear Chimneys originate; free gas is trapped by fault-bound traps formed by tectonic faults or deep-rooted PFs. (b) Gas accumulation in the PF-bound traps in the lower part of PF footwalls; note the possible occurrence of multiple permeable layers filled by gas. (c) Free gas trapped by the lower hanging wall of PFs in which accommodation space was created by fractures or fold during subsidence. 

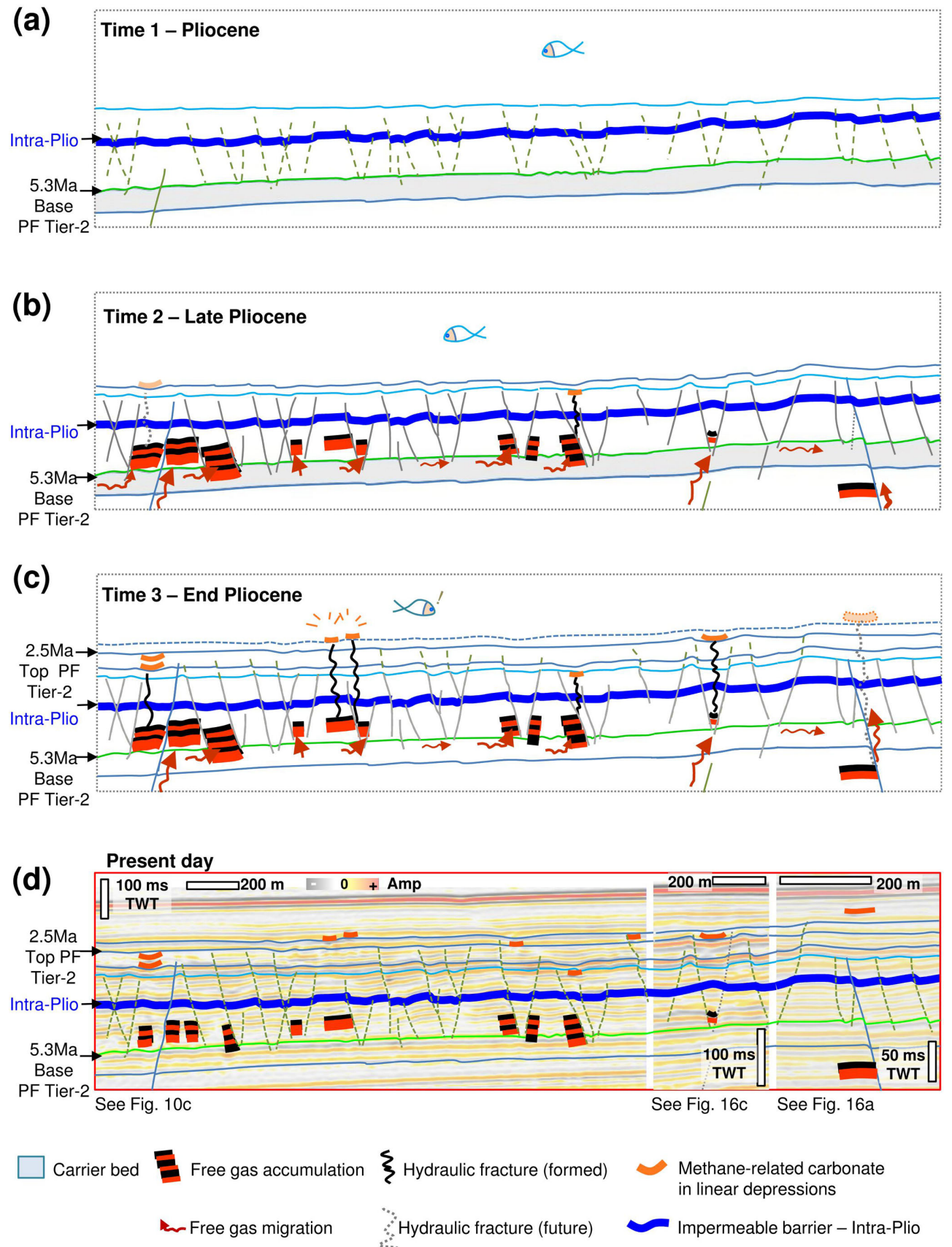

Figure 17. Conceptual model for the time steps of gas migration into the PF tier and the formation of the Linear Venting System (sensu Ho et al., 2012a). (a) Initiation of PFs and deposition of impermeable barrier (Intra-Pliocene). (b) PF tier and associated gas traps formed during the late Pliocene. Gas migrated along tectonic faults, reaching the carrier bed below the PF tier, and then flowed into the PF-bound traps via the roots of PFs. (c) Overpressure in PF-bound traps induced hydraulic fractures, which propagated vertically to the seafloor, i.e. the formation of the Linear Chimney at the end of the Pliocene. Continuous gas expulsion induced the formation of depressions and methanerelated carbonates above the fractures. PFs continue to propagate upwards during sedimentation. New generations of Linear Chimneys and depressions have formed since the end of the Pliocene. (d) The present day state. The whole tier is buried. The drawing of the final stage overlays the corresponding seismic sections.

\subsubsection{Model of fluid migration and Linear Chimney formation}

Linear Chimney formation can be summarised in six steps (Fig. 17). 
(a)

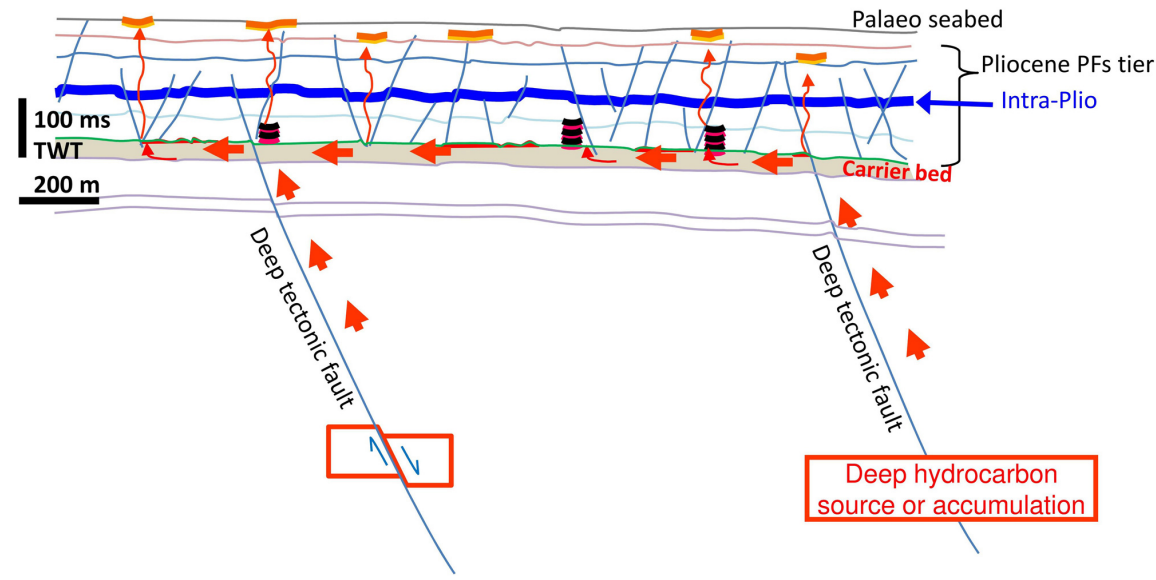

(b) Behaviour of fluid along tectonic fault in area non-polygonal faulted

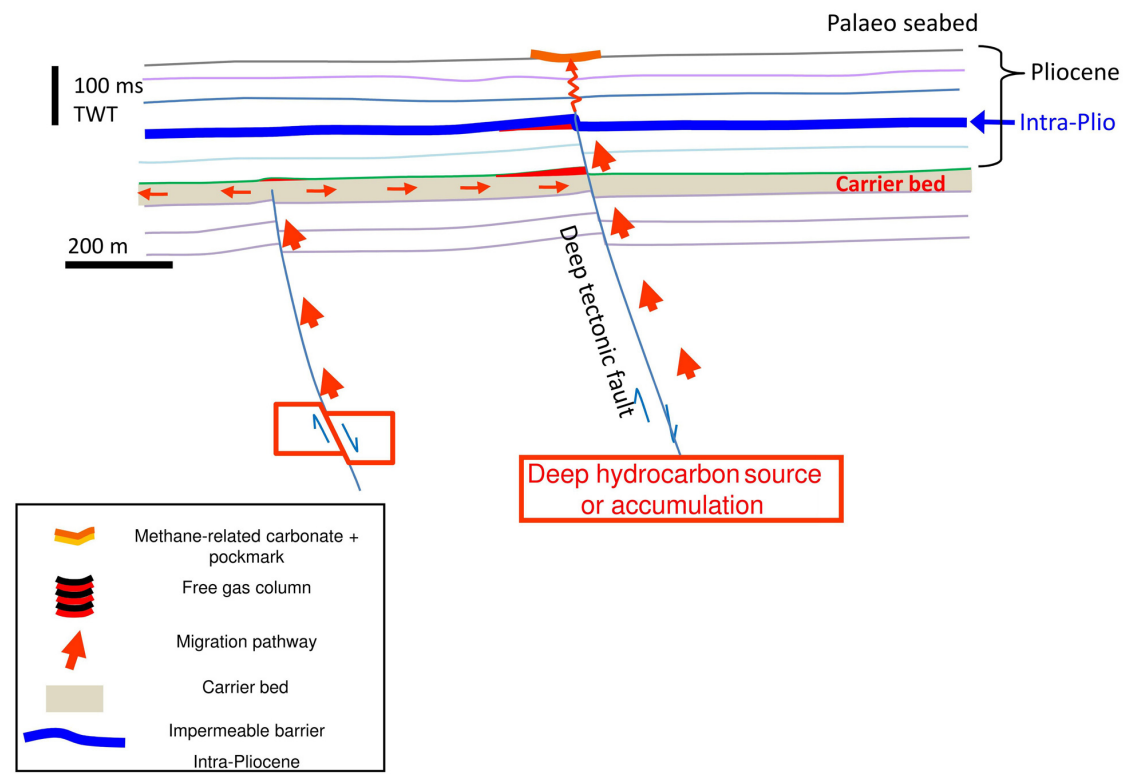

Figure 18. Conceptual models for two styles of gas migration into intervals with or without polygonal faulting. (a) Drawings show the trajectories of gas migration pathways branching out along the bottom of the PF tier. (b) Migration pathways focused along tectonic fault within the Pliocene interval.

1. During the Pliocene, anisotropic PFs formed and developed under the influence of an anisotropic stress field induced by adjacent (salt) tectonic structures.

2. Gas-charged fluids migrated vertically from deeper intervals along tectonic faults and laterally into the permeable beds below or at the base of the PF tier (Fig. 17a).

3. Gas-charged fluids migrated upwards along the root of PFs, then flowed into the lower part of the tier and filled the highest permeable layers in the horst or the fractured apex of grabens where the permeability was higher than in the undamaged sediment (Fig. 17a-b). The pressure of gas-charged fluid was not strong enough to allow gas to intrude the upper part of the PF plane (which is to referred as impermeable). Further upward migration of the gas-charged fluids within strata was prevented by the Intra-Pliocene impermeable interval. 
4. Overpressure of gas-charged fluids attained the threshold value for hydraulic fracture propagation but was insufficient to reactivate the fault.

5. Hydraulic fractures (i.e. chimneys) propagated upward from the lower part of the PF footwall or hanging wall (Fig. 17c) throughout the end of the Pliocene to the Quaternary. These fractures were affected by the stress field around the closest fault and developed a linear planform parallel to adjacent faults (along the direction of the intermediate principal stress).

6. The linear outlet of chimneys on the seafloor was eroded by gas venting, producing a linear depression in which methane-derived authigenic carbonates precipitated and are expressed by PHAAs in seismic data (Fig. 17d).

\subsection{Implications for petroleum exploration}

\subsubsection{Reconstruction of hydrocarbon leakage history by using Linear Chimneys}

This analysis of Linear Chimneys has revealed information about the palaeo-activities of buried hydrocarbon systems, especially how gas-charged fluid interacted with pre-existing geological structures while migrating upward to the subsurface. Based on the analysis of linear venting structures, we attempt to reconstruct the hydrocarbon leakage regime in this study area. Linear venting structures and gas concentrations occur predominantly in the synclines, indicating they are sites of active fluid flow (Figs. 9b, 10b). The reason why gas preferentially concentrates within synclines in the Pliocene PF interval in this study area may be because of coarsergrained sediments trapped in the syncline depocentres during that period. It is also known that synclinal faults cut down to deep turbidite channel reservoirs in this study area (Monnier et al., 2014). Venting structures occurring around the extensional faults of synclines suggest that these faults served as initial leakage pathways for gas-charged fluids to migrate upwards into Tier-2. If the amount of gas exceeds the accommodation volume of the faults, gas will migrate horizontally into shallow carrier beds at the base of PF Tier- 2 and then use the deep-rooted PFs as further leakage pathways into the PF tier (Fig. 18a). This explains why gas accumulations occur within PF Tier-2 above the centre of Syncline-3, mimicking the geometry of the polygonal cells (traps) (Fig. 9b). Within the anisotropic PF network in all syncline locations (e.g. Figs. 10b, 9c), the preferential orientation of linear gas accumulation and hydraulic fractures (i.e. Linear Chimneys) suggests that the direction of gas flowing and escaping within the tier was likely guided by anisotropic stress conditions.

In contrast, where anisotropic PFs are absent, no Linear Chimneys occur. Therefore, gas migrations are likely unaffected by the surrounding stress state because the horizontal principal stresses are too weak or too similar, and instead gas may migrate in random directions until it reaches a permeable bed or mechanically weak zone to break through (Fig. 18b).

To summarise, the direction of fluid leakage in areas of anisotropic PFs can be predicted by analysing fracture and fault directions (Ho, 2013; Ho et al., 2013).

\subsubsection{Reconstruction of palaeo-stress directions}

Linear Chimneys as stress indicators. We have shown that the propagation and resulting morphology of chimneys are receptive to perturbations in magnitude, directions, and differences in the horizontal principal stresses. The ability to date the formation of such systems makes Linear Chimneys potential indicators of palaeo-stress conditions. Normal faults propagate parallel to the intermediate principal stress, while hydraulic fractures also open in parallel to the direction of intermediate principal stresses and against the minimum principal stress (Cosgrove, 1995). For example, in Syncline1 , the orientation of the first-order PFs implies that the direction of the intermediate compressive stress during PF formation was initially following the curvature of the northern edge of Syncline-1 (Fig. 11). However, the subsequently formed Linear Chimneys tend to be parallel to the curvature of the eastern edge. Because hydraulic fractures open in parallel to the intermediate principal stress and as their alignments also indicate the direction of intermediate stress, at the moment that overpressured gas-charged fluids escaped via hydraulic fractures (i.e. Linear Chimneys formed), the intermediate stress direction was likely switched from the northern curvature to the eastern curvature. Thus, the horizontal stress field reoriented during gas leakage after PF formations. Next to the NE side of Syncline-1 is an extensional fault set that is observed to parallel the Linear Chimneys (Fig. 11); it was reactivated during the Plio-Quaternary (red stars in Fig. 2a; Ho, 2013). Because these tectonic faults were active during the same time as the linear conduits formed (in the Pliocene to the beginning of the Quaternary), it is plausible that the reorientation of the stress fields in Syncline-1 resulted from the movement of these faults. In conclusion, comparing the direction of first-order PFs and the direction of Linear Chimneys is useful for diagnosing the evolutional history of stress fields in the past.

Linear PHAAs as stress indicators. We have shown that the planform of chimneys was modulated by the stress field of faults and that kilometre-scale Linear Chimneys are parallel to the tectonic faults in Syncline-0 (Fig. 13a); these chimneys with their lateral tips connect to each other and constitute a complex Linear Chimney network at $9 \mathrm{Ma}$. Their top is marked by a radial-depressional network formed due to further leakage. Methane-related authigenic carbonates that precipitated within the depressional network formed another complex PHAA network and highlighted the radial geometry of the underlying chimney network (Fig. 13b). Therefore, the subsequent flow structures associated with the chimneys that 
have the same planform also appear to be useful to determine the palaeo-principal-stress directions.

\section{Conclusions}

The anisotropic stress attributed to perturbations of the regional stress field by faults and salt diapirism controls the orientation of PFs, which in turn impacts gas-charged fluid accumulation, migration, leakage pathways, and ultimately the geometry of gas leakage conduits and associated expulsion features at the seafloor. The mechanism of Linear Chimney formation is summarised as follows.

1. Fluid expulsion features making the upper termination of chimneys at the palaeo-seafloor (pockmarks/depressions, and seep carbonates) date chimney formation from the end of the Pliocene to the present. Polygonal faulting initiated in the shallow depth range from 50 to $100 \mathrm{~ms}$ TWT below the seafloor during the early Pliocene predates Linear Chimneys.

2. PF blocks form fault-bound gas traps in the lower part of PF tiers.

3. The location of these traps determines the site of gas leakage and hence the nucleation site for vertical chimneys.

4. Linear Chimneys nucleating along the lower part of polygonal fault planes document gas-charged fluids that did not migrate along the upper portion of PF planes, which therefore appear to be impermeable.

5. The linear planform of chimneys is mainly determined by the orientation of the intermediate principal stress around the closest fault. Overpressured gas-charged fluids break through the host rock by pushing aside the host rock towards the direction of minimum principal stress; consequently, Linear Chimneys developed aligned and parallel to the intermediate principal stress and hence tectonic and/or polygonal fault strike.

6. In isotropic stress fields, under the same spectrum of fluid expulsion dynamics, the morphologies of chimneys and associated fluid expulsion features at the seafloor (depressions/pockmarks, seep carbonate bodies) are circular, while they are linear in anisotropic stress fields surrounding tectonic faults, salt structures, and in anisotropic PF networks.

7. In situ stress fields of isotropic PFs alone are not sufficient to induce Linear Chimneys, and anisotropic tectonic stress fields must be involved.

8. In areas experiencing a transition of two stress fields, Linear Chimneys follow the trend of less anisotropic
PFs rather than the nearby tectonic structures. Therefore, the development of Linear Chimneys is interpreted to have been predominantly affected by the in situ stress field of anisotropic PFs (which are dominated by the anisotropic tectonic stress).

9. Linear Chimneys can be used as a tool to reconstruct previous stress directions in the same way as using preferentially orientated PFs.

Data availability. This study is based on the data of statistical analysis shown in Fig. 12. Hence, the data are accessible to the public. The entire 3-D seismic surveys are not accessible to the public because they contain sensitive information. In addition, they are property of the government of Angola, Total S.A. and their affiliates. 
Appendix A

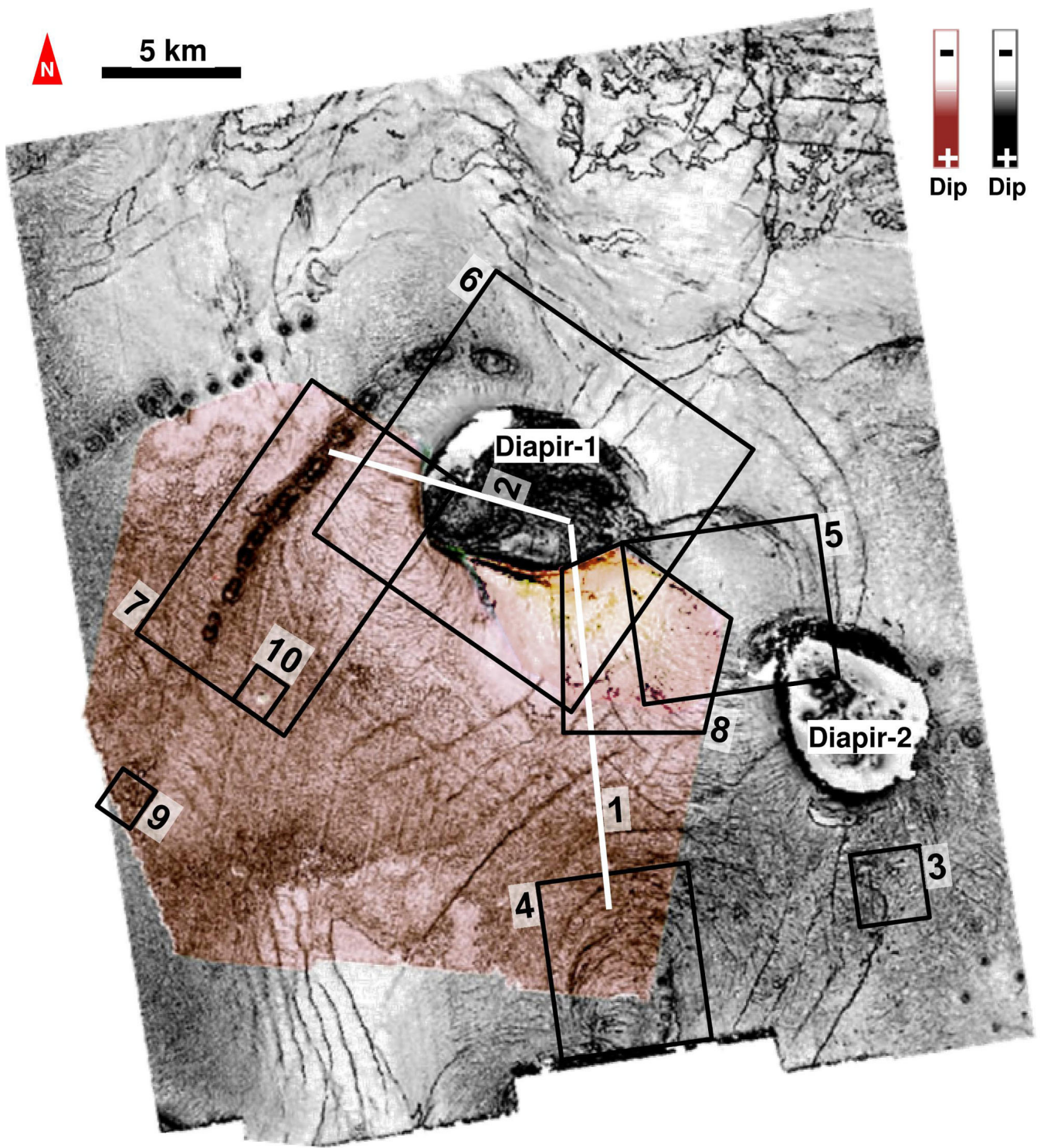

List of areas that have been investigated in previous studies:

\footnotetext{
1) Fig. 1 in $\mathrm{Ho}$ et al. (2013) (see also Appendix-5)

2) Fig. 1 in $\mathrm{Ho}$ et al. (2013)

3) Fig. $2 \mathrm{a}$ in $\mathrm{Ho}$ et al. (2013)
}

4) Fig. $2 d$ in $\mathrm{Ho}$ et al. (2013)
Fig. $2 \mathrm{~b}$ in Ho et al. (2012b)

5) Fig. 2c in Ho et al. (2013)

Fig. $2 \mathrm{~b}$ in $\mathrm{Ho}$ et al. (2016)
6) Fig. 3d in Ho et al. (2013)

7) Fig. $2 \mathrm{a}$ in $\mathrm{Ho}$ et al. (2012b)

8) Fig. 3b in Ho et al. (2012a)

9) Fig. 7b in Ho et al. (2012a)

10) Fig. $8 \mathrm{~b}$ in Ho et al. (2012a)

The high resolution survey corresponds to the pink area.

The regional survey corresponds to the grey area, which Ho (2013) and this study are based on. It is only available from Total S.A

Figure A1. The areas investigated in previous studies (Ho, 2013; Ho et al., 2012, 2013, 2016) are shown on the dip map of horizon 5.3 Ma. Superposition of the high-resolution survey (pink area) and the regional survey (grey area). 

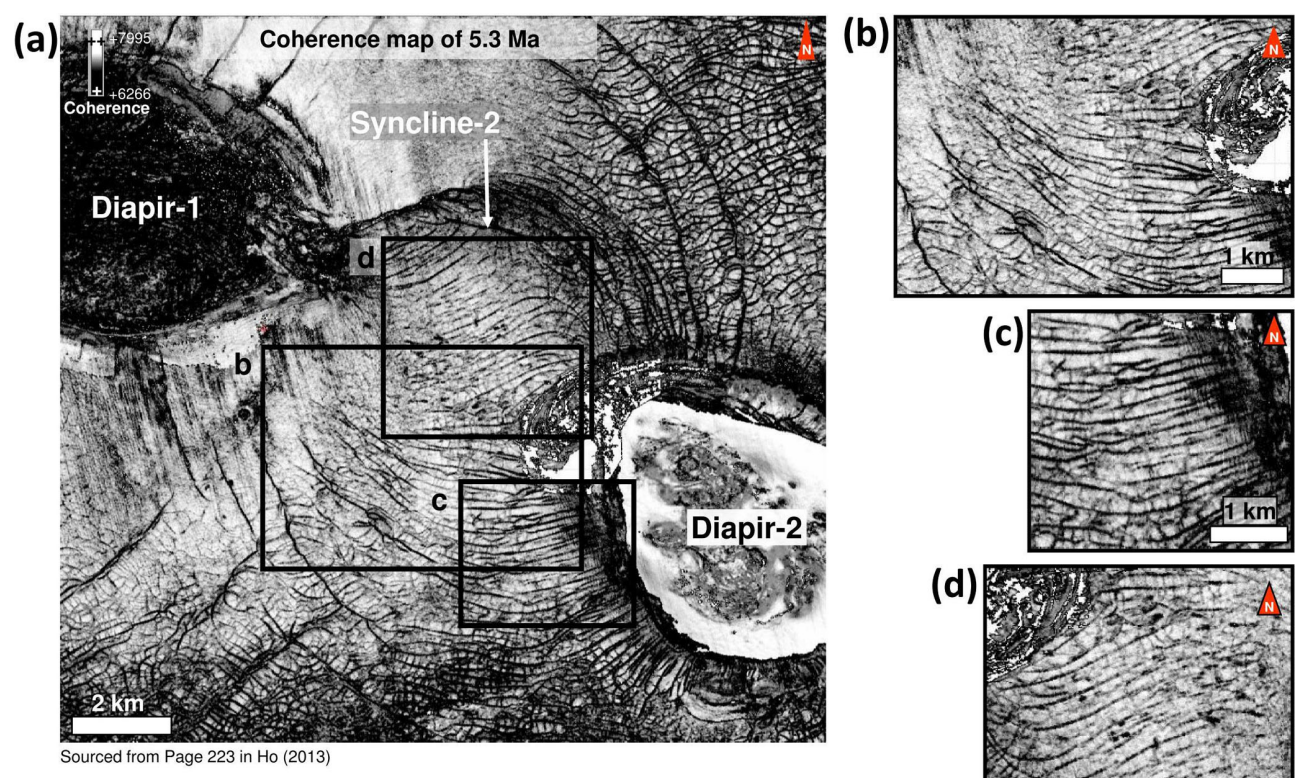

\section{(b) Concentric PFs \\ (c) Radial PFs \\ (d) Ladder-shaped PFs}

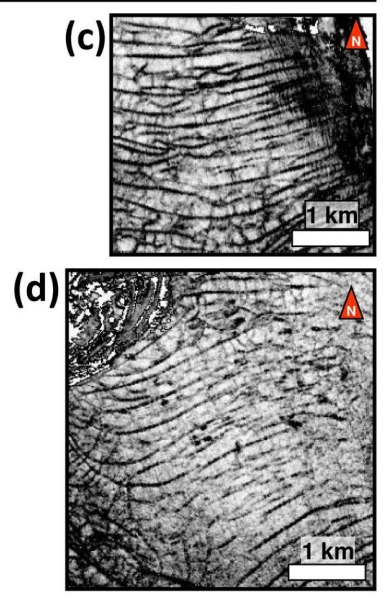

Figure A2. Different patterns of anisotropic PF networks in which Linear Chimneys are found. (a) Coherence attribute extracted onto the basal surface of PF Tier-2 showing the geometry and preferential alignment of PFs in withdrawal Syncline-2 and around Diapir-1 and -2. (b-d) Close-ups of the map in (a). Locations of maps are shown by coloured squares. Sourced from page 223 in Ho (2013). 


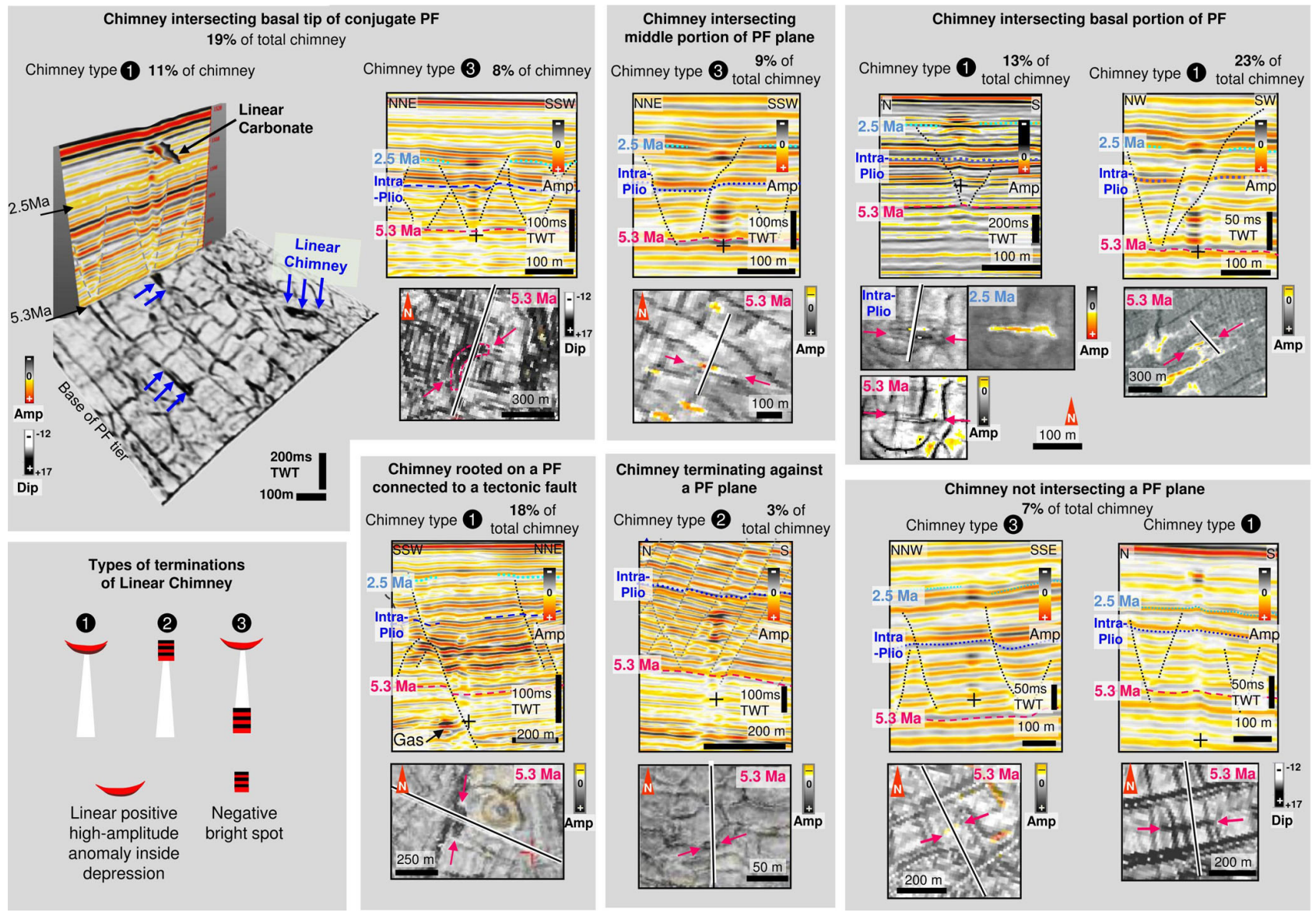

Figure A3. Examples of different groups of chimneys intersecting and emanating from different parts of polygonal faults (PFs). The linear vents of Type-1, 2, and 3 are labelled with black circles. The percentages correspond to the numbers of chimneys intersecting fault planes at specific positions (see pie chart in Fig. 12). The planform dimensions of the chimneys are shown on maps below each section. The apparent bases of chimneys are marked with crosses. See description in Sect. 4.1.1. 


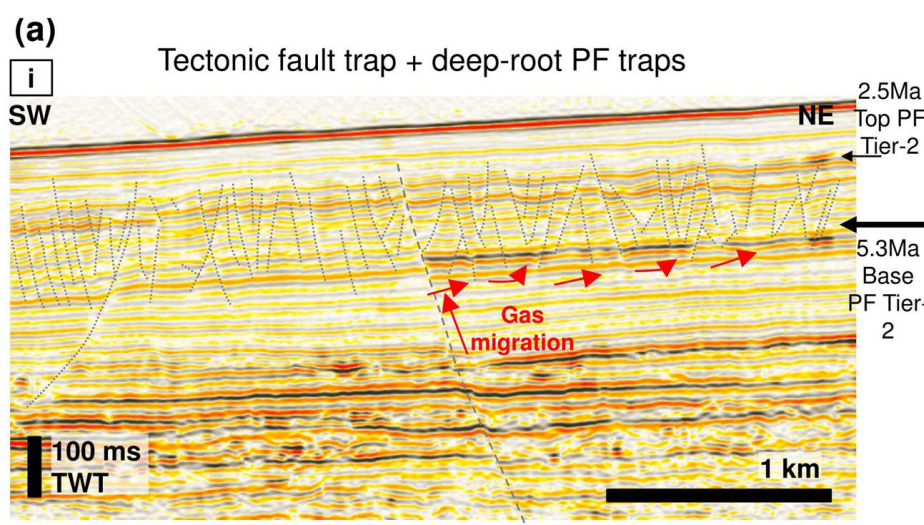

(b)

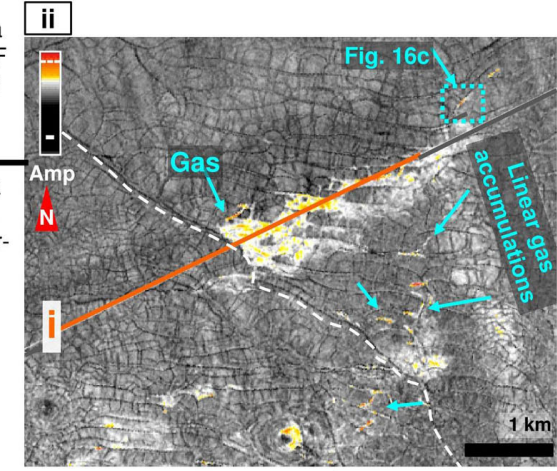

Tectonic fault

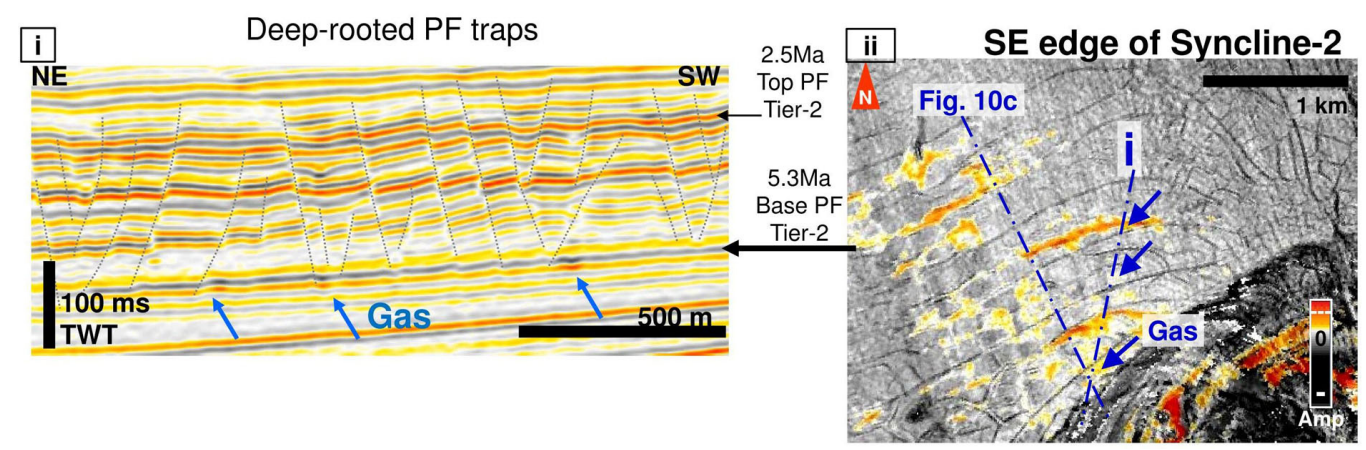

Figure A4. Linear patches of negative high amplitudes interpreted as gas accumulation at the base of PF Tier-2. (a) Free gas interpreted to have migrated along a tectonic fault and flowed preferentially into a permeable interval at the base of Tier- 2 in the higher elevation (i.e. tectonic fault trap) as shown on the seismic profile (i). Note that the deep-rooted PFs extend deeper than the tier (forming PF traps). (ii) The amplitude map along the base of Tier-2 shows that gas had actually filled the whole PF cell trap. (b) Gas occurs around the bottom of deep-rooted long PFs as shown (i) and exhibit linear planforms on the amplitude map of the Tier-2 base (ii). 
Supplement. The supplement related to this article is available online at: https://doi.org/10.5194/se-9-1437-2018-supplement.

Competing interests. The authors declare that they have no conflict of interest.

Acknowledgements. We thank Total S.A. for providing data and funding, Total S.A. and its partners for publication permission, and the Ministry of Science and Technology of Taiwan for the grant MOST1052914I002069A1. Our work is based on and extended from chapter 6 of Sutieng Ho's PhD. The scientific work was fully carried out at Total S.A., France, and completed under their direction. Sutieng Ho thanks Benoit Paternoster for his supervision in geophysics since 2007. Sutieng Ho thanks Mads Huuse for reviewing Sutieng Ho's $\mathrm{PhD}$, and Cardiff University for partial $\mathrm{PhD}$ funding. We are grateful for enormous support and valuable advice from Timothy Byrne, David Hutchings, Quentin Vannelle, Ludvig Löwemark, and Char-Shine Liu. Special thanks go to our English editor, Sebastian Czarnota Konrad, for his English language guidance and proofreading services in the last few years. We thank Andreia Plaza-Faverola and two reviewers for their helpful comments. This work had previously been submitted to Marine Geology on 23 January 2017 and retrieved by us in 2018 due to an extensive delay in the revision process.

Edited by: Elias Samankassou

Reviewed by: Andreia Plaza-Faverola and two anonymous referees

\section{References}

Barnett, J. A., Mortimer, J., Rippon, J. H., Walsh, J. J., and Watterson, J.: Displacement geometry in the volume containing a single normal fault, AAPG Bull., 71, 925-937, 1987.

Berkson, J. M. and Clay, C.: Possible syneresis origin of valleys on the floor of Lake Superior, Nature, 245, 89-91, 1973.

Berndt, C., Bünz, S., and Mienert, J.: Polygonal fault systems on the mid-Norwegian margin: a long-term source for fluid flow, Geol. Soc. Spec. Publ., 216, 283-290, 2003.

Berndt, C., Jacobs, C., Evans, A., Gay, A., Elliott, G., Long, D., and Hitchen, K.: Kilometre-scale polygonal seabed depressions in the Hatton Basin, NE Atlantic Ocean: Constraints on the origin of polygonal faulting, Mar. Geol., 332, 126-133, 2012.

Blouet, J.-P., Imbert, P., and Foubert, A.: Mechanisms of biogenic gas migration revealed by seep carbonate paragenesis, Panoche Hills, California, AAPG Bull., 101, 1309-1340, 2017.

Bose, S. and Mitra, S.: Analog modeling of divergent and convergent transfer zones in listric normal fault systems, AAPG Bull., 94, 1425-1452, 2010.

Bouriak, S., Vanneste, M., and Saoutkine, A.: Inferred gas hydrates and clay diapirs near the Storegga Slide on the southern edge of the Vøring Plateau, offshore Norway, Mar. Geol., 163, 125-148, 2000.

Broucke, O., Temple, F., Rouby, D., Robin, C., Calassou, S., Nalpas, T., and Guillocheau, F.: The role of deformation processes on the geometry of mud-dominated turbiditic systems, Oligocene and
Lower-Middle Miocene of the Lower Congo basin (West African Margin), Mar. Petrol. Geol., 21, 327-348, 2004.

Bureau, D.: Modalité mécaniques de la formation des intrusions de sable, Doctoral dissertation, Université du Maine, Le Maine, France, 2014.

Carruthers, D., Cartwright, J., Jackson, M. P., and Schutjens, P.: Origin and timing of layer-bound radial faulting around North Sea salt stocks: New insights into the evolving stress state around rising diapirs, Mar. Petrol. Geol., 48, 130-148, 2013.

Carruthers, T.: Interaction of polygonal fault systems with salt diapirs, doctoral dissertation, Cardiff University, Cardiff, UK, 489 pp., 2012.

Cartwright, J. A.: Episodic basin-wide hydrofracturing of overpressured Early Cenozoic mudrock sequences in the North Sea Basin, Mar. Petrol. Geol., 11, 587-607, 1994.

Cathles, L. M., Su, Z., and Chen, D.: The physics of gas chimney and pockmark formation, with implications for assessment of seafloor hazards and gas sequestration, Mar. Petrol. Geol., 27, 82-91, 2010.

Cevatoglu, M., Bull, J. M., Vardy, M. E., Gernon, T. M., Wright, I. C., and Long, D.: Gas migration pathways, controlling mechanisms and changes in sediment acoustic properties observed in a controlled sub-seabed $\mathrm{CO}_{2}$ release experiment, Int. J. Greenh. Gas Con., 38, 26-43, 2015.

Chopra, S. and Marfurt, K. J.: Seismic attributes for prospect identification and reservoir characterization, Society of Exploration Geophysicists and European Association of Geoscientists and Engineers, Tulsa, USA, 2007.

Clausen, J., Gabrielsen, R., Reksnes, P., and Nysaether, E.: Development of intraformational (Oligocene-Miocene) faults in the northern North Sea: influence of remote stresses and doming of Fennoscandia, J. Struct. Geol., 21, 1457-1475, 1999.

Cloos, E.: Experimental analysis of Gulf Coast fracture patterns, AAPG Bull., 52, 420-444, 1968.

Coffeen, J.: Seismic exploration fundamentals, Penwell Press, Tulsa, USA, 1978.

Cosgrove, J.: The expression of hydraulic fracturing in rocks and sediments, Geol. Soc. Spec. Publ., 92, 187-196, 1995.

Davison, I., Alsop, I., Birch, P., Elders, C., Evans, N., Nicholson, H., Rorison, P., Wade, D., Woodward, J., and Young, M.: Geometry and late-stage structural evolution of Central Graben salt diapirs, North Sea, Mar. Petrol. Geol., 17, 499-522, 2000.

Delaney, P. T., Pollard, D. D., Ziony, J. I., and McKee, E. H.: Field relations between dikes and joints: emplacement processes and paleostress analysis, J. Geophys. Res.-Sol. Ea., 91, 4920-4938, 1986.

Duval, B., Cramez, C., and Jackson, M.: Raft tectonics in the Kwanza basin, Angola, Mar. Petrol. Geol., 9, 389-404, 1992.

Fossen, H. and Rørnes, A.: Properties of fault populations in the Gullfaks Field, northern North Sea, J. Struct. Geol., 18, 179-190, 1996.

Fredrich, J. T., Coblentz, D., Fossum, A. F., and Thorne, B. J.: Stress perturbations adjacent to salt bodies in the deepwater Gulf of Mexico, in: Proceeding of SPE Annual Technical Conference and Exhibition, Denver, Colorado, 5-8 October 2003, SPE 84554, 2003.

Gaffney, E. S., Damjanac, B., and Valentine, G. A.: Localization of volcanic activity: 2. Effects of pre-existing structure, Earth Planet. Sc. Lett., 263, 323-338, 2007. 
Gay, A., Lopez, M., Cochonat, P., Sultan, N., Cauquil, E., and Brigaud, F.: Sinuous pockmark belt as indicator of a shallow buried turbiditic channel on the lower slope of the Congo basin, West African margin, Geol. Soc. Spec. Publ., 216, 173-189, 2003.

Gay, A., Lopez, M., Cochonat, P., Séranne, M., Levaché, D., and Sermondadaz, G.: Isolated seafloor pockmarks linked to BSRs, fluid chimneys, polygonal faults and stacked Oligocene-Miocene turbiditic palaeochannels in the Lower Congo Basin, Mar. Geol., 226, 25-40, 2006.

Gay, A., Lopez, M., Berndt, C., and Séranne, M.: Geological controls on focused fluid flow associated with seafloor seeps in the Lower Congo Basin, Mar. Geol., 244, 68-92, 2007.

Ghalayini, R., Homberg, C., Daniel, J. M., and Nader, F. H.: Growth of layer-bound normal faults under a regional anisotropic stress field. Geol. Soc. Spec. Publ., 439, 57-78, 2006.

Goulty, N.: Geomechanics of polygonal fault systems: a review, Petrol. Geosci., 14, 389-397, 2008.

Heggland, R.: Detection of gas migration from a deep source by the use of exploration 3-D seismic data, Mar. Geol., 137, 41-47, 1997.

Heggland, R.: Definition of geohazards in exploration 3-D seismic data using attributes and neural-network analysis, AAPG Bull., 88, 857-868, 2004.

Heggland, R.: Using gas chimneys in seal integrity analysis: A discussion based on case histories, in: Evaluating Fault and Cap Rock Seals, edited by: Boult, P. and Kaldi, J., AAPG Hedberg Series, 2, American Association of Petroleum Geologists, Tulsa, USA, 2005.

Henriet, J.-P., D’olier, B., Auffret, J., and Andersen, H.: Seismic tracking of geological hazards related to clay tectonics in the Southern Bight of the North Sea, IZWO Collected Reprints, 12, 1982.

Henriet, J., De Batist, M., and Verschuren, M.: Early fracturing of Palaeogene clays, southernmost North Sea: relevance to mechanisms of primary hydrocarbon migration, Generation, Accumulation and Production of Europe's Hydrocarbons, 1, 217-227, 1991.

Henriet, J., De Batist, M., Van Vaerenbergh, W., and Verschuren, M.: Seismic facies and clay tectonic features of the Ypresian clay in the southern North Sea, Bulletin van de Belgische Vereniging voor Geologie, 97, 457-472, 1988.

Ho, S., Cartwright, J., and Imbert, P.: Vertical evolution of fluid venting structures in relation to gas flux, in the NeogeneQuaternary of the Lower Congo Basin, Offshore Angola, Mar. Geol., 332, 40-55, 2012.

Ho, S., Cartwright, J., and Imbert, P.: The formation of advancing pockmarks arrays: an interplay between hydrocarbon leakage and slope sedimentation, in: Proceeding of American Association of Petroleum Geologists Annual Convention and Exhibition, Long Beach, USA, 18-20 September 2012, 1-10, 2012.

Ho, S.: Evolution of complex vertical successions of fluid venting systems during continental margin sedimentation, doctoral dissertation, Cardiff University Cardiff, UK, 2013.

Ho, S., Carruthers, T., Imbert, P., and Cartwright, J.: Spatial Variations in Geometries of Polygonal Faults Due to Stress Perturbations and Interplay with Fluid Venting Features, in: Proceeding of 75th EAGE Conference and Exhibition incorporating SPE EUROPEC 2013, London, UK, 10-13 June 2013, 1-6, 2013.
Ho, S., Carruthers, D., and Imbert, P.: Insights into the permeability of polygonal faults from their intersection geometries with Linear Chimneys: a case study from the Lower Congo Basin, Carnets Geol., 16, 17-26, 2016.

Ho, S., Imbert, P., Hovland, M., Wetzel, A., Blouet, J. P., and Carruthers, D.: Downslope-shifting pockmarks: interplay between hydrocarbon leakage, sedimentations, currents and slope's topography, Int. J. Earth Sci., 107, 1-23, 2018.

Hovland, M.: Elongated depressions associated with pockmarks in the western slope of the Norwegian Trench, Mar. Geol., 51, 3546, 1983.

Hovland, M.: Gas-induced erosion features in the North Sea, Earth Surf. Proc. Land., 9, 209-228, 1984.

Hustoft, S., Mienert, J., Bünz, S., and Nouzé, H.: High-resolution $3-$ D-seismic data indicate focussed fluid migration pathways above polygonal fault systems of the mid-Norwegian margin, Mar. Geol., 245, 89-106, 2007.

Hustoft, S., Bünz, S., Mienert, J., and Chand, S.: Gas hydrate reservoir and active methane-venting province in sediments on $<20$ Ma young oceanic crust in the Fram Strait, offshore NWSvalbard, Earth Planet. Sc. Lett., 284, 12-24, 2009.

Hustoft, S., Bünz, S., and Mienert, J.: Three-dimensional seismic analysis of the morphology and spatial distribution of chimneys beneath the Nyegga pockmark field, offshore mid-Norway, Basin Res., 22, 465-480, 2010

Imbert, P. and Ho, S.: Seismic-scale funnel-shaped collapse features from the Paleocene-Eocene of the North West Shelf of Australia, Mar. Geol., 332, 198-221, 2012.

Imbert, P., Casenave, V., Blouet, J. P., and Ho, S.: Hydrocarbon Leakage through Fine-grained Series-Focused vs. Distributed. In 79th EAGE Conference and Exhibition 2017, Paris, France, 12 15 June 2017.

Jacobs, C.: An appraisal of the surface geology and sedimentary processes within SEA7, the UK continental shelf, National Oceanography Centre, Southampton, Research and Consultancy Report No. 18, 127 pp., 2006.

Judd, A. and Hovland, M.: Seabed fluid flow: the impact on geology, biology and the marine environment, Cambridge University Press, Cambridge, UK, 2007.

Kaproth, B. M., Kacewicz, M., Muhuri, S., and Marone, C.: Permeability and frictional properties of halite-clay-quartz faults in marine-sediment: The role of compaction and shear, Mar. Petrol. Geol., 78, 222-235, 2016.

Kattenhorn, S. A., Aydin, A., and Pollard, D. D.: Joints at high angles to normal fault strike: an explanation using 3-D numerical models of fault-perturbed stress fields, J. Struct. Geol., 22, 1-23, 2000.

King, R., Backé, G., Tingay, M., Hillis, R., and Mildren, S.: Stress deflections around salt diapirs in the Gulf of Mexico, Geol. Soc. Spec. Publ., 367, 141-153, 2012.

Laurent, D., Gay, A., Baudon, C., Berndt, C., Soliva, R., Planke, S., Mourgues, R., Lacaze, S., Pauget, F., and Mangue, M.: Highresolution architecture of a polygonal fault interval inferred from geomodel applied to 3-D seismic data from the Gjallar Ridge, Vøring Basin, Offshore Norway, Mar. Geol., 332, 134-151, 2012.

Ligtenberg, J.: Detection of fluid migration pathways in seismic data: implications for fault seal analysis, Basin Res., 17, 141153, 2005. 
Løseth, H., Wensaas, L., Arntsen, B., Hanken, N., Basire, C., and Graue, K.: $1000 \mathrm{~m}$ long gas blow-out pipes, in: Proceeding of 63rd EAGE Conference and Exhibition, Amsterdam, the Netherlands, 11-15 June 2001, P524, 1-4, 2001.

Løseth, H., Gading, M., and Wensaas, L.: Hydrocarbon leakage interpreted on seismic data, Mar. Petrol. Geol., 26, 1304-1319, 2009.

Løseth, H., Wensaas, L., Arntsen, B., Hanken, N.-M., Basire, C., and Graue, K.: $1000 \mathrm{~m}$ long gas blow-out pipes, Mar. Petrol. Geol., 28, 1047-1060, 2011.

Mascle, J. and Phillips, J. D.: Magnetic Smooth Zones in the South Atlantic, Nature, 240, 80-84, 1972.

Monnier, D., Imbert, P., Gay, A., Mourgues, R., and Lopez, M.: Pliocene sand injectites from a submarine lobe fringe during hydrocarbon migration and salt diapirism: a seismic example from the Lower Congo Basin, Geofluids, 14, 1-19, 2014.

Moore, J. C., Orange, D., and Kulm, L. D.: Interrelationship of fluid venting and structural evolution: Alvin observations from the frontal accretionary prism, Oregon, J. Geophys. Res.-Sol. Ea., 95, 8795-8808, 1990.

Moss, J. L.: The spatial and temporal distribution of pipe and pockmark formation, Doctoral dissertation, Cardiff University, Cardiff, UK, 432 pp., 2010.

Nakamura, K.: Volcanoes as possible indicators of tectonic stress orientation-principle and proposal, J. Volcanol. Geoth. Res., 2, 1-16, 1977.

Nunn, J. A.: Pore-pressure-dependent fracture permeability in fault zones: implications for cross-formational fluid flow, Multidimensional basin modeling: AAPG, of AAPG Datapages, Discovery Series, 7, 89-103, 2003.

Ostanin, I., Anka, Z., di Primio, R., and Bernal, A.: Identification of a large Upper Cretaceous polygonal fault network in the Hammerfest basin: Implications on the reactivation of regional faulting and gas leakage dynamics, SW Barents Sea, Mar. Geol., 332, 109-125, 2012.

Petersen, C. J., Bünz, S., Hustoft, S., Mienert, J., and Klaeschen, D.: High-resolution P-Cable 3-D seismic imaging of gas chimney structures in gas hydrated sediments of an Arctic sediment drift, Mar. Petrol. Geol., 27, 1981-1994, 2010.

Phillips, W. J.: Hydraulic fracturing and mineralization, J. Geol. Soc., 128, 337-359, 1972.

Philippe, Y.: Angola SE Corner, Central Area And SW Corner: Teriary Regional Structural Synthesis, Elf Exploration, Internal report, 72 pp., 2000.

Plaza-Faverola, A., Bünz, S., and Mienert, J.: Fluid distributions inferred from P-wave velocity and reflection seismic amplitude anomalies beneath the Nyegga pockmark field of the midNorwegian margin, Mar. Petrol. Geol., 27, 46-60, 2010.

Plaza-Faverola, A., Bünz, S., and Mienert, J.: Repeated fluid expulsion through sub-seabed chimneys offshore Norway in response to glacial cycles, Earth Planet. Sc. Lett., 305, 297-308, 2011.

Plaza-Faverola, A., Bünz, S., and Mienert, J.: The free gas zone beneath gas hydrate bearing sediments and its link to fluid flow: 3D seismic imaging offshore mid-Norway, Mar. Geol., 291, 211226, 2012.

Plaza-Faverola, A., Bünz, S., Johnson, J. E., Chand, S., Knies, J., Mienert, J., and Franek, P.: Role of tectonic stress in seepage evolution along the gas hydrate-charged Vestnesa Ridge, Fram Strait, Geophys. Res. Lett., 42, 733-742, 2015.
Pollard, D. D. and Aydin, A.: Progress in understanding jointing over the past century, Geol. Soc. Am. Bull., 100, 1181-1204, 1988.

Pyrak-Nolte, L.: The seismic response of fractures and the interrelations among fracture properties, in: Proceeding of International journal of rock mechanics and mining sciences and geomechanics abstracts, Great Britain, 787-802, 1996.

Rawnsley, K., Rives, T., Petti, J.-P., Hencher, S., and Lumsden, A.: Joint development in perturbed stress fields near faults, J. Struct. Geol., 14, 939-951, 1992.

Regnier, P., Dale, A. W., Arndt, S., LaRowe, D., Mogollón, J., and Van Cappellen, P.: Quantitative analysis of anaerobic oxidation of methane (AOM) in marine sediments: a modeling perspective, Earth-Sci. Rev., 106, 105-130, 2011.

Roberts, H. H. and Carney, R. S.: Evidence of episodic fluid, gas, and sediment venting on the northern Gulf of Mexico continental slope, Econ. Geol., 92, 863-879, 1997.

Roberts, H. H., Hardage, B. A., Shedd, W. W., and Hunt Jr., J.: Seafloor reflectivity - an important seismic property for interpreting fluid/gas expulsion geology and the presence of gas hydrate, The Leading Edge, 25, 620-628, 2006.

Sanz, P. and Dasari, G.: Controls on in-situ stresses around salt bodies, in: Proceeding of 44th US Rock Mechanics Symposium and 5th US-Canada Rock Mechanics Symposium, Salt Lake City, Utah, 27-30 June 2010, ARMA-10-169, 2010.

Séranne, M., and Anka, Z.: South Atlantic continental margins of Africa: a comparison of the tectonic vs climate interplay on the evolution of equatorial west Africa and SW Africa margins, J. Afr. Earth Sci., 43, 283-300, 2005.

Sonnenberg, S., Underwood, D., Peterson, M., Finley, E., Kernan, N., and Harris, A.: Polygonal faults, Niobrara Formation, Denver Basin, in: Proceeding of AAPG Annual Convention and Exhibition, Calgary, Canada, 19-22 June 2016, 51311, 2016.

Stewart, S. A.: Implications of passive salt diapir kinematics for reservoir segmentation by radial and concentric faults, Mar. Petrol. Geol., 23, 843-853, 2006.

Talukder, A. R.: Review of submarine cold seep plumbing systems: leakage to seepage and venting, Terra Nova, 24, 255-272, 2012.

Thrasher, J., Fleet, A. J., Hay, S. J., Hovland, M., and Düppenbecker, S.: Understanding geology as the key to using seepage in exploration: the spectrum of seepage styles, in: Hydrocarbon Migration and its Near-Surface Expression, AAPG Memoir 66, AAPG, Tulsa, USA, 1996.

van Gent, H. W., Holland, M., Urai, J. L., and Loosveld, R.: Evolution of fault zones in carbonates with mechanical stratigraphyInsights from scale models using layered cohesive powder, J. Struct. Geol., 32, 1375-1391, 2010.

Verschuren, M.: An integrated 3-D approach to clay tectonic deformation and the development of a new 3-D modeling method, University of Ghent, 359 pp., 1992.

Welch, M. J., Knipe, R. J., Souque, C., and Davies, R. K.: A Quadshear kinematic model for folding and clay smear development in fault zones, Tectonophysics, 471, 186-202, 2009.

Wiprut, D. and Zoback, M. D.: Fault reactivation and fluid flow along a previously dormant normal fault in the northern North Sea, Geology, 28, 595-598, 2000.

Zhang, Y., Gartrell, A., Underschultz, J., and Dewhurst, D.: Numerical modelling of strain localisation and fluid flow during exten- 
sional fault reactivation: Implications for hydrocarbon preservation, J. Struct. Geol., 31, 315-327, 2009.
Zoback, M. D.: Reservoir geomechanics: Earth stress and rock mechanics applied to exploration, production and wellbore stability, Cambridge Press, Cambridge, UK, 2007. 